\title{
The Assignment and Division of the Tax Base in a System of Hierarchical Governments
}

\author{
William H. Hoyt \\ CESIFO WORKING PAPER NO. 5801 \\ CATEGORY 1: PUBliC FinANCE \\ MARCH 2016 \\ An electronic version of the paper may be downloaded \\ - from the SSRN website: Www.SSRN.com \\ - from the RePEc website: Www.RePEc.org \\ - from the CESifo website: www.CESifo-group.org/wp
}




\title{
The Assignment and Division of the Tax Base in a System of Hierarchical Governments
}

\begin{abstract}
Vertical externalities, changes in one level of government's policies that affect the budget of another level of government, may lead to non-optimal government policies. These externalities are associated with tax bases that are shared or "co-occupied" by two levels of government. Here I consider whether the co-occupancy of tax bases is desirable. I examine the optimal extent of the tax bases of a lower level of government (local) and a higher level (state). I find that it is optimal to have co-occupancy in the absence of other corrective policies if commodities in tax base are substitutes. Further, if the state government can differentially tax the co-occupied segment of the tax base and the segment it alone taxes it will obtain the (second-best) outcome obtained with other policy instruments such as intergovernmental grants. Finally, if there are horizontal externalities generated by cross-border shopping, there is still reason to co-occupy the tax base if commodities are substitutes. As well, local governments should have those commodities with the lowest cross-border shopping costs in their tax base.
\end{abstract}

JEL-Codes: H200, H710, H730, R120, R280, R410.

Keywords: fiscal competition, vertical externalities, tax base co-occupancy.

\author{
William H. Hoyt \\ Department of Economics \\ Gatton College of Business and Economics \\ University of Kentucky \\ USA - Lexington, KY 40506 \\ whoyt@uky.edu
}

This Version: February 2016

Thanks to David Agrawal, Robert Inman, participants at the 2015 National Tax Association meetings, and the University of Kentucky Department of Economics workshop. 


\section{Introduction}

While the concept of a horizontal fiscal externality arising from tax competition among governments at the same level has been the topic of numerous papers in for more than thirty years, the focus on "vertical" fiscal externalities received later attention. Among the early theoretical contributions were Johnson (1988) and Flowers (1988) and continued with Dahlby (1996, 2008), Boadway and Keen (1996), Boadway, Marchand and Vigneault (1998). More recent contributions include Boadway, Cuff and Marchand (2003), Keen (1998), Keen and Kotsogiannis (2002, 2003, 2004), Hoyt (2001), Dahlby and Wilson (2003), Wrede (1996, 2000), Keen and Kotsogiannis (2002), and Wilson and Janeba (2005) among others.

As the name vertical implies, these externalities arise between governments at different levels, for example, between state and local governments or federal and state governments. In this case the focus is on the overlap in the tax bases of two levels of government. An example from Dahlby (1996) is the excise tax placed on cigarettes by both the federal and state governments in the United States. When choosing its tax rate, each state presumably only considers the tax's impact on its own revenues and ignores the impact on the revenues of other states and the federal government. As a result of an increase in the state's tax rate, other states tax revenues will increase because of cross-border shopping (a horizontal externality) and federal tax revenues will be reduced because of the reduction in the cigarettes purchases, part of their tax base (a vertical externality). Because of these impacts on the revenues of other governments, the cost of funds perceived by the state differs from the social cost of the funds. While the horizontal fiscal externality is positive, the vertical externality is negative as increases in the state tax reduce federal revenues. Because the state government ignores this negative externality, it will overtax cigarettes.

A number of studies have considered policies by the higher level of government to correct for the vertical externalities created by taxes imposed by the lower level of government. Corrective policies include separating the tax bases of the two levels of government (Flowers (1988)); increasing the number of lower-level governments (Keen (1995); Keen and Kotsogiannis (2004)); and providing intergovernmental grants (Dahlby (1996); Boadway and Keen (1996); Boadway, Marchand and Vigneault (1998); and Flochel and Madies (2002)).

While early studies focused on vertical externalities in a single market, research has extended to consider the impacts of co-occupancy in a multiple market including studies by Dahlby (1996), Keen (1998), Hoyt (2001), Dahlby, Mintz and Wilson (2000), and Dahlby (2001), and Dahlby and Wilson (2003). While I also examine tax policies in a hierarchical system of governments, I depart from previous studies in a several respects. First I consider vertical externalities with multiple tax bases. Specifically, I consider a large number (a 
continuum) of commodities to be included in either or both of levels of governments tax bases. The consideration of multiple commodities enables us to address the question of central interest to this paper - how should the tax base be allocated between the two levels of government?

Vertical fiscal externalities act in both directions - state taxes affect local revenues and local taxes affect state revenues. Flowers (1988), Wrede (1996), and Keen and Kotsogiannis (2002), for example, assume that both levels of government ignore the vertical externality imposed on the other level of government when setting tax policies. This leads to excessive taxation at both levels of government. Here, I consider both the case in which the state government considers the impact of its tax policies on local revenues as well as the case in which it does not. Figure 1 illustrates the fiscal externality imposed by an increase of a local tax on state government revenues.

In addition to having multiple tax bases, different levels of governments rely on very different sources of revenue. As Table 1 suggestions, while there is only limited overlap or co-occupancy in sources of revenue of state and local governments in the United States, for example, there is likely to be a strong link between their alternative tax bases. Changes in a major source of state revenue such as the personal income tax will undoubtedly affect revenues from the property tax, a major local source of revenue. In contrast, there is much more apparent co-occupancy of the federal and state tax bases primarily because the personal income tax and, to a lesser extent, the corporate income tax are major sources of tax revenue for both levels of government. Thus, while vertical fiscal externalities will almost certainly arise in a co-occupied tax base, it does not follow that eliminating co-occupancy eliminates fiscal externalities, an idea that may underlie the recommendation by some to eliminate cooccupancy. In fact, eliminating co-occupancy may change the fiscal externality from being negative to being positive if the commodities in the two tax bases are substitutes. This, in turn, would suggest under-taxation rather than over-taxation in the framework developed here.

The issue addressed here, what level of government should tax what goods or services or inputs is referred to in the federalism literature as the "assignment" problem. In a surprisingly small literature, the best known discussion of the appropriate assignment of the tax base in a system of hierarchical governments may be found in Musgrave (1983) with nice summaries in Musgrave and Musgrave (1989), Oates (1994), Keen (1998) and Dahlby (2001). While Musgrave provided some general guidelines for assigning tax bases based on the elasticity of alternative tax bases, he does not discuss how vertical fiscal externalities might affect assignment. Keen (1998) does devote some discussion (and analysis) to cooccupancy and assignment by addressing the question of whether it is better to co-occupy 
an inelastic tax base or a more elastic tax base. Dahlby (2001) raises several concerns with Musgrave's rules for assignment including the issue of co-occupancy. While not presenting any formal model, Dahlby (2001), by highlighting the general interdependency of tax bases, raises questions similar to those I address here. In very different contexts both Haufler and Lulfesmann (2015) and Kotsogiannis and Raimondos (2015) consider "optimal" cooccupancy. However, in both cases, the co-occupancy corrects for horizontal externalities: in the case of Haufler and Lulfesmann (2015) these are associated with capital taxation by asymmetric countries and in the case of Kotsogiannis and Raimondos (2015) countries levy taxes to change the terms of trade.

An extensive literature on the possible efficacy of co-occupancy has addressed issues related to horizontal fiscal externalities and cross-jurisdictional trade distortions as a result of lower-level government tax policies. Perhaps the most extensive discussion of the tax assignment issue has been related to the VAT taxation and the issue of source versus destination taxation. Contributions to this literature include Bird (2000); Bird and Gendron (1998, 2000); Keen (2000) and Keen and Smith (2000). Recent related contributions to notion of higher-level government taxation "correcting" for inefficiencies associated with lower-level government policies include Haufler and Lulfesmann (2015) and Kotsogiannis and Raimon$\operatorname{dos}(2015)$.

Here I address the assignment question using a very different framework from those in either Musgrave (1983) or Keen (1998) but similar in many ways to the framework implicit in Dahlby (2001). Rather than considering the type of tax base that should be taxed by different levels of government, I first consider how to divide a uniform tax base among two levels of government and whether co-occupancy is desirable or not. While this very simple framework means that I ignore many of the issues associated with tax assignment such as geography, benefit taxation, and cross-border shopping discussed in, for example, Bird (2000) and McLure (2001) it allows for focus on the question of whether the existence of vertical fiscal externalities might, as suggested by Flowers (1988) and Dahlby (2001) among others, lead to the conclusion that there should be no or very limited co-occupancy among tax bases. Even when the elimination of co-occupancy may be optimal, it does not, in general, eliminate vertical fiscal externalities. As a consequence, even in the absence of co-occupancy the tax rates of the two levels of government will not be optimally set. If the commodities in the tax base are gross substitutes, eliminating co-occupancy results in a positive fiscal externality, meaning that tax rates will become "too" low. Here, because both the tax rates and tax bases of governments are policy instruments, I need to distinguish between fiscal externalities associated with changes in a government's tax rate and one associated with changes in its tax base. While the division of the tax base obviously influences the vertical externalities 
associated with the tax rates, the extent and direction of the fiscal externalities associated with tax increases and those associated with increases in tax bases can be quite different. In fact, I find that in the case in which commodities are gross substitutes, co-occupancy, at least to some extent, is optimal; when commodities are gross complements, it is unlikely that co-occupancy is optimal.

The basic model, found in Section 2, is of a continuum of commodities with identical demands along the lines, for example, of Dixit and Stiglitz (1977), Yitzhaki (1979), and Wilson (1989). In this section I motivate the optimal policies with regard to both the tax rate and base by considering the policy undertaken by a single, central government that finances two public services with separate taxes. I then consider the alternative extreme - the choices of tax rates and tax bases made by the two levels of government (state and local) when they choose them independently. As I assume that commodities are identical both governments will set uniform tax rates on their respective bases. ${ }^{1}$ In Section 3 the optimal tax bases (from their perspective) for the two levels of government is considered. In this section I first consider the question of how to divide the tax base between the two levels of government in the absence of any overlap. I then consider whether and under what conditions, would co-occupancy be socially optimal. As well, I allow for the possibility that the state government can set different tax rates on the base that it alone taxes and the base that it shares (co-occupies) with the local government. Finally, in Section 4 I extend the model to generate a horizontal externality. In this case, along the lines of Agrawal (2012) and Nielsen (2001), for example, I allow for cross-border shopping. In addition to generating a horizontal externality, as I allow for differences in the costs of cross-border shopping among commodities, I can also address the question of what commodities might be included in the state and local tax bases rather than simply the extent of the two bases and whether co-occupancy is optimal. Section 5 concludes.

\section{Tax Choices with Independent Governments}

\subsection{A Simple Model}

I consider an economy with a single state government and $n$ local governments with each locality having a single, identical resident. Each government provides a public service to its residents with $g_{s}$ being the level provided by the state government and $g_{j}, j=1, \ldots, n$ the

\footnotetext{
${ }^{1}$ Further assumptions regarding the elasticity of the demands of the products are necessary for this result as will be seen later. Alternatively, that there are uniform tax rates across commodities can also be considered an assumption reflecting (most) state and local sales tax in the United States and VAT systems elsewhere as discussed in ?.
} 
level provided by locality $j$. Both public services are produced with constant costs with the cost of providing $g_{s}$ to the $n$ localities equal to $n g_{s}$ and the cost of providing the local public service in locality $j$ equal to $g_{j}$. While there are $n$ independent localities, as each local government has the same policy objectives, in equilibrium all localities choose the same policies. Then given this symmetry, I denote local policies by the subscript $l$. To further simplify the analysis, I also assume that the number of localities is large enough so that no individual locality considers the impacts its policies have on state revenues.

In addition to the public services, residents also consume private commodities. Following Dixit and Stiglitz (1977), Yitzhaki (1979), and Wilson (1989), I consider a continuum of these private commodities identified on the interval $[0, K]$. While the interval of commodities is $[0, K]$ only the interval $[0,1]$ is subject to taxation by either the state or local governments. ${ }^{2}$ As my interest is in how to allocate the tax base between the two levels of government, like Dixit and Stiglitz (1977) I assume identical demand functions over the set of commodities. By this I mean that when the prices of two commodities are identical, the quantity demanded is the same for both. The utility function can be represented by

$$
U=\int_{0}^{K}\left(U^{x}(x(q(k), Q)) d k+U^{l}\left(g_{l}\right)+U^{s}\left(g_{s}\right)\right.
$$

The gross of tax price of commodity $k, x(k)$, is denoted by $q(k)$ with the net of tax prices for all commodities equal to unity. The term $Q=\left(\int_{0}^{K} q(k) d k\right)$ is an index of all commodity prices. Unlike Dixit and Stiglitz (1977), I assume a relatively general form of the utility function. As the demand function for commodities are identical then when the price of commodity $i$ and commodity $j$ are the same, their demands are the same. I denote the derivatives of the demand equations by $x_{11} \equiv \frac{\partial x(k)}{\partial q(k)}$ and $x_{21} \equiv \frac{\partial x(k)}{\partial Q}$ and, what will be used when characterizing tax rates, the percentage change in demands, $\widehat{x}_{11} \equiv \frac{\partial x(k)}{\partial q(k)} \frac{1}{x(k)}$ and $\widehat{x}_{21} \equiv \frac{\partial x(k)}{\partial Q} \frac{1}{x(k)}$ that I treat as constant in the analysis. For my purposes, an important implication of having identical commodities is that the optimal tax structure is extremely simple - all commodities should be taxed equally.

As both the local and state governments assess uniform commodity taxes to finance their public services, the gross price of each commodity depends on whether it is part of the tax base for the local, state, or both governments. Localities tax the set of commodities on the interval $\left[0, \bar{k}_{l}\right]$ while the set taxed by the state government is on the interval $\left[\bar{k}_{s}, 1\right]$. Let $k_{l}, k_{s}$, and $k_{l s}$ denote, respectively, the length of interval taxed only be the local government,

\footnotetext{
${ }^{2}$ While we may think of the commodity space as a straight line or circle, like Dixit and Stiglitz (1977) the distance between any two commodities has no bearing on the relationship between them, that is, the degree to which they are substitutes or complements. This is seen in the formulation of the price index.
} 
only by the state government, and by both levels of government. Then the gross of tax price for the commodities can be summarized by

$$
q(k)=\left\{\begin{array}{cc}
1+\tau_{l}, & k \in 0,\left[\min \left(\bar{k}_{l}, \bar{k}_{s}\right)\right) \\
1+\tau_{s}, & k \in\left[\max \left(\bar{k}_{l}, \bar{k}_{s}\right), 1\right] \\
1+\tau_{l}+\tau_{s}, & k \in\left[\bar{k}_{s}, \bar{k}_{l}\right] \text { if }, \bar{k}_{l}>\bar{k}_{s}
\end{array}\right.
$$

where $\tau_{l}$ and $\tau_{s}$ denote the local and state tax rates respectively. ${ }^{3}$ Figure 2 illustrates the division of the tax base with no overlap (no co-occupancy) and with overlap (co-occupancy).

Then the indirect utility function can be expressed $\mathrm{as}^{4}$

$$
V\left[\tau_{l}, \tau_{s}, \bar{k}_{s}, \bar{k}_{l}\right]=\int_{0}^{K} V(q(k), Q) d k+U^{s}\left(g_{s}\left(\tau_{l}, \tau_{k}, \bar{k}_{s}, \bar{k}_{l}\right)\right)+U^{l}\left(g_{l}\left(\tau_{l}, \tau_{k}, \bar{k}_{s}, \bar{k}_{l}\right)\right)
$$

\subsubsection{Government Objectives}

The objective function for local governments is given by

$$
W^{l}\left[\tau_{l}, \tau_{s}, \bar{k}_{l}, \bar{k}_{s}\right]=\int_{0}^{K} V(q(k), Q) d k+U^{l}\left(g_{l}\left(\tau_{l}, \tau_{s}, \bar{k}_{l}, \bar{k}_{s}\right)\right)
$$

where the level of the local public service is implicitly defined by the state and local tax rates and bases, $g_{l}\left(\tau_{l}, \tau_{s}, \bar{k}_{l}, \bar{k}_{s}\right)$. As local governments are assumed to ignore the impact of their policies on state revenues, state public services are not included as an argument in the local government's welfare functions.

\footnotetext{
${ }^{3}$ With these taxes the price index is

$$
Q=\left\{\begin{array}{ccc}
\int_{0}^{\bar{k}_{s}}\left(1+\tau_{l}\right) d k+\int_{\bar{k}_{s}}^{\bar{k}_{l}}\left(1+\tau_{l}+\tau_{s}\right) d k+\int_{\bar{k}_{l}}^{1}\left(1+\tau_{s}\right) d k+\int_{1}^{K} d k & \bar{k}_{l}>\bar{k}_{s} \\
=K+k_{l} \tau_{l}+k_{s} \tau_{s}+k_{l s}\left(\tau_{l}+\tau_{s}\right) & \\
\int_{0}^{\bar{k}_{l}}\left(1+\tau_{l}\right) d k+\int_{\bar{k}_{l}}^{\bar{k}_{s}} d k+\int_{\bar{k}_{s}}\left(1+\tau_{s}\right) d k+\int_{1}^{K} d k & \bar{k}_{l}<\bar{k}_{s} \\
=K+k_{l} \tau_{l}+k_{s} \tau_{s} &
\end{array}\right.
$$
}

${ }^{4}$ where the term

$$
\int_{0}^{1} V(q(k), Q) d k=\left\{\begin{array}{c}
\int_{0}^{\bar{k}_{l}} U^{x}\left(x\left(q(k)=1+\tau_{l}, Q\right)\right) d k+\int_{\bar{k}_{l}}^{\bar{k}_{s}} U^{x}(x(q(k)=1, Q)) d k \\
+\int_{\bar{k}_{s}}^{1} U^{x}\left(x\left(q(k)=1+\tau_{s}, Q\right)\right) d k+\int_{1}^{K} U^{x}(x(q(k)=1, Q)) d k \\
\int_{0}^{\bar{k}_{s}} U^{x}\left(x\left(q(k)=1+\tau_{l}, Q\right)\right) d k+\int_{\bar{k}_{l}}^{\bar{k}_{s}} U^{x}\left(x\left(q(k)=1+\tau_{l}+\tau_{s}, Q\right)\right) d k \\
+\int_{\bar{k}_{s}}^{1} U^{x}\left(x\left(q(k)=1+\tau_{s}, Q\right)\right) d k+\int_{1}^{K} U^{x}(x(q(k)=1, Q)) d k
\end{array}, \bar{k}_{l}>\bar{k}_{s}\right.
$$


For the state government consider the objective,

$$
W^{s}\left[\tau_{l}, \tau_{s}, \bar{k}_{l}, \bar{k}_{s}\right]=\int_{0}^{K} V(q(k), Q) d k+U^{s}\left(g_{s}\left(\tau_{l}, \tau_{s}, \bar{k}_{s}, \bar{k}_{l}\right)\right)+\alpha U^{l}\left(g_{l}\left(\tau_{l}, \tau_{s}, \bar{k}_{s}, \bar{k}_{l}\right)\right)
$$

where $\alpha \in[0,1]$. The parameter $\alpha$ denotes the extent that the state government considers the impacts of its policies on the local government revenues. If $\alpha=1$ the state government fully considers the impacts of its policies on local revenues and the welfare of its residents; at the other extreme $(\alpha=0)$ the state ignores the impacts of its policies on local revenues and public services. My interest will be focused on these two extreme cases.

\subsubsection{Government Budget Constraints}

The state budget constraint is given by $n g_{s}=n \tau_{s}\left(k_{s} x_{s}+k_{l s} x_{l s}\right)=n \tau_{s} X_{s}$ and the local budget constraint is given by $g_{l}=\tau_{l}\left(k_{l} x_{l}+k_{l s} x_{l s}\right)=\tau_{l} X_{l}$ where $x_{s}, x_{l}$, and $x_{l s}$ denote the demand for commodities subject to the state tax only, to the local tax only, and to both taxes, respectively.

Critical to understanding the tax rates chosen by the two levels of government and the optimal tax bases for them is understanding the impacts of changes in their tax rates and bases on their revenues. These impacts, summarized below, are derived in Appendix A.1.

$$
\begin{aligned}
\frac{d g_{j}}{d \tau_{j}} & =X_{j}\left[1+\tau_{j}\left(\widehat{x}_{11}+\left(k_{j}+k_{l s}\right) \widehat{x}_{21}\right)\right] \text { and } \\
\frac{d g_{i}}{d \tau_{j}} & =\tau_{i} X_{i}\left[\frac{k_{l s}}{\left(k_{l s}+k_{i}\right)} \frac{x_{l s}}{\bar{x}_{i}} \widehat{x}_{11}+\left(k_{j}+k_{l s}\right) \widehat{x}_{21}\right], i, j=, l s ; i \neq j
\end{aligned}
$$

where $\bar{x}_{i}=\frac{k_{l s} x_{l s}+k_{i} x_{i}}{k_{l s}+k_{i}}, i=l, s$. Note that the sign and magnitude of the fiscal externalities, $\frac{d g_{i}}{d \tau_{j}}, i, j=l, s ; i \neq j$ depend on both the overlap in the tax based $\left(k_{l s}\right)$ and cross-price effects $\left(\widehat{x}_{21}\right)$. While the focus of the literature on fiscal externalities has been on tax rates, I am also interested in the impacts of changes in tax bases of the two levels of government. Then the impacts of increases in the tax base on revenues are

$$
\frac{d g_{j}}{d \bar{k}_{j}}=\tau_{j} \bar{x}_{j}\left[\frac{x_{z}}{\bar{x}_{j}}+\tau_{l}\left(k_{l s}+k_{j}\right) \widehat{x}_{21}\right] \text { and } \frac{d g_{i}}{d \bar{k}_{j}}=\tau_{j} \tau_{i} \bar{x}_{i}\left[D \frac{x_{i}}{x_{j}} \widehat{x}_{11}+\left(k_{l s}+k_{i}\right) \widehat{x}_{21}\right], i, j=l, s ; i \neq j,
$$

where $D=0(1)$ and $z=j(l s)$ if $\bar{k}_{l}<(>) \bar{k}_{s}, j=l, s .{ }^{5}$ As is the case with tax rates, changes in the tax bases of the two levels of government affect tax revenues of the other level of government. The impact of the expansion of the tax base by one level of government on the other levels tax revenue depends on whether the two tax bases overlap and the cross-price

\footnotetext{
${ }^{5}$ An increase in the state tax base means a decrease in $\bar{k}_{s}$ so rather than $\frac{d g_{s}}{d \bar{k}_{s}}$ and $\frac{d g_{l}}{d \bar{k}_{s}}(2.7)$ is for $-\frac{d g_{s}}{d \bar{k}_{s}}$ and $-\frac{d g_{l}}{d \bar{k}_{s}}$.
} 
elasticities (impacts) among commodities, relative to their own price elasticities - when the two tax bases overlap, increases in the local (state) tax base will always decrease the state (local) tax base.

\subsection{Centralized Solution}

Before considering the tax policies chosen when governments are making independent policy decisions, I first consider the choices of a single government providing both services. While the obvious policy would be to impose a uniform rate on the entire tax base to finance both services, to provide a contrast to the policy choices of independent governments, consider the choices when the single government finances the two services, $g_{l}$ and $g_{s}$, by two separate taxes, $\tau_{l}$ and $\tau_{s}$ on two distinct, though possibly overlapping tax bases. The government's problem, then, is

$$
\begin{gathered}
\operatorname{Max} \\
\tau_{l}, \tau_{s}, \bar{k}_{l}, \bar{k}_{s}
\end{gathered} \quad W\left[\tau_{l}, \tau_{s}, \bar{k}_{l}, \bar{k}_{s}\right]=\int_{0}^{1} V(q(k), Q) d k+U^{s}\left(g_{s}\left(\tau_{l}, \tau_{s}, k_{s}, k_{l}\right)\right)+U^{l}\left(g_{l}\left(\tau_{l}, \tau_{s}, k_{s}, k_{l}\right)\right)
$$

The first order conditions with respect to the state tax rate can be expressed as

$$
W_{\tau_{l}=} \begin{gathered}
\left(M R S_{s}-1\right)+M R S_{s} \tau_{s}\left(\widehat{x}_{11}+\left(k_{s}+k_{l s}\right) \widehat{x}_{21}\right) \\
+M R S_{l} \tau_{l}\left[\frac{X_{l}}{X_{s}}\right]\left(\left(\frac{k_{l s}}{k_{l}+k_{l s}}\right) \frac{x_{l s}}{\bar{x}_{l}} \widehat{x}_{11}+\left(k_{s}+k_{l s}\right) \widehat{x}_{21}\right)
\end{gathered}=0
$$

and with respect to the local tax rate by

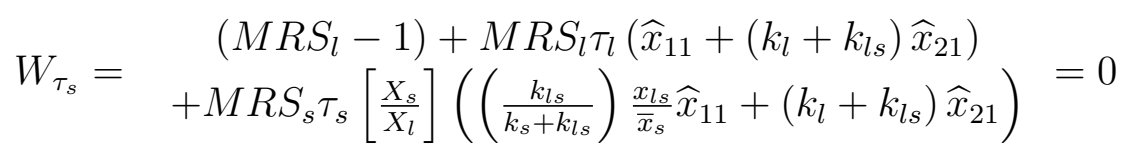

where $M R S_{j}=\frac{\frac{\partial V}{\partial g_{j}}}{\frac{\partial V}{\partial y}}, j=l, s$ is the marginal rate of substitution between public service $j$ and private consumption. ${ }^{6}$ The derivations of (2.9) and (2.10) as well as those for other first order conditions and proofs of propositions in the remainder of the section are found in Appendix A.2. Rather than stating the first order conditions for the tax bases, two characteristics of the solution should be evident: the marginal rates of substitution of the two goods should be equal $\left(M R S_{l}=M R S_{s}\right)$ and the tax rate on all commodities should be the same. Then given only two distinct tax rates, to have equal rates on all commodities, either both levels of government tax the entire base $\left(k_{l s}=1\right)$ or there is no overlap $\left(k_{l s}=0\right)$. When commodities are either gross substitutes or complements $\left(\hat{x}_{21} \neq 0\right)$ it is not possible

\footnotetext{
${ }^{6}$ I suppress $\frac{\partial V}{\partial y}$ from all expressions of first order conditions as it has no bearing on the analysis.
} 
to tax all commodities with no overlap $\left(k_{s}=1-k_{l}\right)$, have equal tax rates $\left(\tau_{l}=\tau_{s}\right)$, and equal marginal rates of substitution, $\left(M R S_{l}=M R S_{s}\right)$. Note that when the two tax bases completely overlap, the taxes still have negative fiscal externalities, that is, increases in one of the tax rates will reduce tax revenues from the other tax.

Proposition 1. When a central government finances the "local" public service $\left(g_{l}\right)$ from revenues of the local tax $\left(\tau_{l}\right)$ on the local tax base $\left(X_{l}\right)$ and finances the "state" public service $\left(g_{s}\right)$ from revenues of the state tax $\left(\tau_{s}\right)$ on the state tax base $\left(X_{s}\right)$ the optimal policy is to apply both taxes to the entire tax base $\left(\bar{k}_{l}=1\right.$ and $\left.\bar{k}_{s}=0\right)$.

With this policy, the marginal rate of substitution is equal for both services $\left(M R S_{l}=M R S_{s}\right)$ and all commodities are taxed equally. Again, the result is not surprising given that the central government internalizes the cross-tax impacts on revenues. However, it does suggest that distinct taxes and overlapping tax bases are not necessarily a concern.

\subsection{Fiscal Externalities and Tax Rates}

As discussed, the co-occupancy of tax bases generates negative fiscal externalities and, as a result, may lead to over-provision of public services when the externalities are not internalized in the policy decisions of the government. Less noted in the literature are the fiscal externalities associated with taxation of bases that are not co-occupied. If the two tax bases are substitutes then it is a positive externality; if complements, a negative fiscal externality. I begin, then, by illustrating the nature of the fiscal externalities associated with taxes in the context of this model. First I focus on the tax rates each government chooses when facing a restricted tax base. Next I consider the possibility that governments can choose both their tax rates and bases.

\subsubsection{Local Tax Policy}

Each locality maximizes its residents' welfare by choosing its tax rate given the tax rates and bases of the other localities and the state government. Its choice of tax rate also depends on the extent of its tax base. Formally the local government's problem is to choose $\tau_{l}$ to solve (2.4). Then in Nash equilibrium, the first order condition for the local tax rate $\left(\tau_{l}\right)$ can be expressed as

$$
\begin{gathered}
W_{\tau_{l}}^{l}=-1+M R S_{l}\left[1+\tau_{l}^{*}\left(\widehat{x}_{11}+\left(k_{l}+k_{l s}\right) \widehat{x}_{21}\right)\right]=0 \text { or } \\
M R S_{l}=\frac{1}{\left[1+\tau_{l}^{*}\left(\widehat{x}_{11}+\left(k_{l}+k_{l s}\right) \widehat{x}_{21}\right)\right]}=\frac{1}{D_{L}}
\end{gathered}
$$


where $\tau_{l}^{*}$ is the equilibrium local tax rate. The marginal external cost $\left(M E C_{\tau_{l}}\right)$ associate with the tax of a single locality is

$$
M E C_{\tau_{l}}=\frac{1}{n} \tau_{s} M R S_{s} X_{s}\left(\left(\frac{k_{l s}}{k_{s}+k_{l s}}\right) \frac{x_{l s}}{\bar{x}_{s}} \widehat{x}_{11}+\left(k_{l s}+k_{l}\right) \widehat{x}_{21}\right)
$$

The $M E C_{\tau_{l}}$ is simply the welfare value associated with an increase or decrease in level of the state public good. From (2.12) it is apparent that $M E C_{\tau_{l}}$ is negative (positive) if

$$
\left(\frac{k_{l s}}{\left(k_{s}+k_{l s}\right)\left(k_{l s}+k_{l}\right)}\right) \frac{x_{l s}}{\bar{x}_{s}}>(<) \frac{-\widehat{x}_{21}}{\widehat{x}_{11}}
$$

If $\widehat{x}_{21}<0$, that is, the goods in the tax base are complements, $M E C_{\tau_{l}}$ will be negative; if goods in the tax base are substitutes $\left(\widehat{x}_{21}>0\right)$ then the sign of $M E C_{\tau_{l}}$ depends on the extent of the overlap in the two tax bases and the ratio of the cross-price and own-price impacts on demand, $\frac{-\widehat{x}_{21}}{\widehat{x}_{11}}$.

\subsubsection{State Tax Policy}

In the Nash equilibrium the first order condition for the state tax rate $\left(\tau_{s}\right)$ can be expressed as

$$
\begin{gathered}
W_{\tau_{s}}^{s}=\left[\begin{array}{c}
-1+M R S_{s}\left[1+\tau_{s}^{*}\left(\widehat{x}_{11}+\left(k_{l}+k_{l s}\right) \widehat{x}_{21}\right]\right. \\
+\alpha M R S_{l} \tau_{l}^{*}\left[\frac{X_{l}}{X_{s}}\right]\left[\left(\left(\frac{k_{l s}}{\left(k_{l s}+k_{l}\right)}\right) \frac{x_{l s}}{\bar{x}_{l}} \widehat{x}_{11}+\left(k_{s}+k_{l s}\right) \widehat{x}_{21}\right)\right]
\end{array}=0\right. \text { or } \\
M R S_{s}=\frac{1-\alpha M R S_{l} \tau_{l}^{*}\left[\left[\frac{X_{l}}{X_{s}}\right]\left(\left(\frac{k_{l s}}{\left(k_{l s}+k_{l}\right)}\right) \frac{x_{l s}}{\bar{x}_{l}} \widehat{x}_{11}+\left(k_{s}+k_{l s}\right) \widehat{x}_{21}\right)\right]}{D_{S}}
\end{gathered}
$$

where $\tau_{s}^{*}$ is the equilibrium state tax rate and $D_{s}=\left[1+\tau_{s}^{*}\left(\widehat{x}_{11}+\left(k_{s}+k_{l s}\right) \widehat{x}_{21}\right)\right]$. As seen in (2.14) if $\alpha>0$ the state considers the effects of its tax rate on local revenues. The impact of the state tax on the local tax base is analogous to that of the local government. However, as the state government may internalize some of the impact of its tax rate on local revenues,

the extent, though not the sign, of the external cost associated with an increase in the state tax depends on the value of $\alpha$ with

$$
M E C_{\tau_{s}}=(1-\alpha) M R S_{l} \tau_{l} X_{l}\left(\left(\frac{k_{l s}}{\left(k_{l s}+k_{l}\right)}\right) \frac{x_{l s}}{\bar{x}_{l}} \hat{x}_{11}+\left(k_{s}+k_{l s}\right) \hat{x}_{21}\right) .
$$

These results are summarized below:

\section{Proposition 2.}

a) If $\alpha \neq 1 M E C_{j}>(<) 0$ if $-\left(\frac{k_{l s}}{\left(k_{l s}+k_{j}\right)}\right) \frac{x_{l_{s}}}{\bar{x}_{j}} \hat{x}_{11}>(<) \hat{x}_{21}, j, i=l, s, i \neq j$; 
b) If the state maximizes social welfare $(\alpha=1) M E C_{s}=0$

c) If $\alpha=0$ then $M R S_{l}>1$ and $M R S_{s}>1$ and $M R S_{s}>(<) M R S_{l}$ if $\tau_{s}^{*}\left(\hat{x}_{11}+\left(k_{s}+k_{l s}\right) \hat{x}_{21}\right)<$ $(>) \tau_{l}^{*}\left(\hat{x}_{11}+\left(k_{l}+k_{l s}\right) \hat{x}_{21}\right)$.

d) If $\alpha \neq 0$ :

i) $M R S_{s}>(<) M R S_{l}$ if $\left\{\begin{array}{c}\tau_{l}^{*}\left[\left(\hat{x}_{11}+\left(k_{l}+k_{l s}\right) \hat{x}_{21}\right)-\alpha\left[\frac{X_{l}}{X_{s}}\right]\left(k_{l s} \frac{X_{l s}}{X_{l}} \hat{x}_{11}+\left(k_{s}+k_{l s}\right) \hat{x}_{21}\right)\right] \\ >(<) \tau_{s}^{*}\left(\hat{x}_{11}+\left(k_{s}+k_{l s}\right) \hat{x}_{21}\right) .\end{array}\right\}$

ii) $M R S_{l}>1$ and if $\left(\frac{k_{l s}}{\left(k_{l s}+k_{l}\right)}\right) \frac{x_{l s}}{\bar{x}_{l}} \hat{x}_{11}+\left(k_{l s}+k_{s}\right) \hat{x}_{21}<0$ then $M R S_{s}>1$.

Part c) of the proposition simply states that when $\alpha=0$ whichever base has the greatest (absolute value) percentage loss in its tax base from a marginal increase in its tax rate will have the greater $M R S$. As seen in part d), when $\alpha \neq 0$ the relationship between the $M R S$ and the changes in tax bases is more complicated as the state considers how changes in its tax rate affect the local base. If there is a positive (negative) fiscal externality, then it is possible for $M R S_{s}<(>) M R S_{l}$ even if $\tau_{l}^{*}\left(\hat{x}_{11}+\left(k_{l}+k_{l s}\right) \hat{x}_{21}\right)<(>) \tau_{s}^{*}\left(\hat{x}_{11}+\left(k_{s}+k_{l s}\right) \hat{x}_{21}\right)$. While the $M R S_{l}>1$ for any tax base for the local government, whether $M R S_{s}$ is greater or less than one depends on two impacts - the magnitude of the decrease in the state tax base due to the tax increase $\left(\hat{x}_{11}+\left(k_{s}+k_{l s}\right) \hat{x}_{21}\right) X_{s}$ and the impact on the local tax base $X_{l s} \hat{x}_{11}+\left(k_{l s}+k_{s}\right) X_{l} \hat{x}_{21}$. If the increase in the state tax reduce the local tax base then it must be the case that $M R S_{s}>1$.

\subsection{Fiscal Externalities and the Choice of Tax Base}

In the United States, the choice of tax base, that is what local governments can tax, is generally at the discretion of state, not local, governments. While this may be the case, it is still useful to examine what tax base local governments would choose if given the option. Here I begin by considering the problem facing local and state governments when they can choose both their tax rate and base.

\subsubsection{Local Tax Base}

Each locality maximizes its residents' welfare by choosing both its tax rate and tax base given the tax rates and bases of the other localities and the state government. As discussed, the optimal tax rate is given by (2.11). In the Nash equilibrium the local welfare-maximizing tax base $\left(\bar{k}_{l}^{*}\right)$ satisfies the first order condition,

$$
\left(1-\bar{k}_{l}^{*}\right) W_{\bar{k}_{l}}^{l}=\left(1-\bar{k}_{l}^{*}\right) \tau_{l}^{*}\left[\left(M R S_{l}-1\right) x_{z}+\tau_{l}^{*} M R S_{l} X_{l} \hat{x}_{21}\right]=0,
$$

where $z=l s, l$ if $\bar{k}_{l}>(<) \bar{k}_{s}$. As $M R S_{l}-1>0$ at the optimal tax rate, as is evident from (2.16) if $\hat{x}_{21}>0$ it must be the case that (2.16) is only satisfied when $\bar{k}_{l}^{*}=1$ - the local 
government chooses to tax the entire base. As shown in the Appendix, if $\hat{x}_{21}<0$ it is still optimal to tax the entire base.

\subsubsection{State Tax Base}

The optimal tax base for the state is characterized by the first order condition,

$$
\bar{k}_{s}^{*} W_{k_{s}}^{s}=\bar{k}_{s}^{*} \tau_{s}^{*}\left[\begin{array}{c}
\left(M R S_{s}-1\right) x_{z}+M R S_{s} \tau_{s}^{*} X_{s} \hat{x}_{21} \\
+\alpha M R S_{l} \tau_{l}^{*}\left(D \hat{x}_{11}+X_{l} \hat{x}_{21}\right)
\end{array}\right]=0,
$$

where $z=l s(s)$ and $D=1(0)$ if $\bar{k}_{l}>(<) \bar{k}_{s}$. Using the first order condition for the state tax rate (2.14) we can express $(2.17)$ as

$$
\bar{k}_{s}^{*} W_{k_{s}}^{s}=\bar{k}_{s}^{*} \tau_{s}^{*} \bar{x}_{s}\left[\left(M R S_{s}-1\right)\left(\frac{x_{z}}{\bar{x}_{s}}-1\right)-M R S_{s} \tau_{s}^{*} \hat{x}_{11}+\alpha M R S_{l} \tau_{l}^{*} D\left(\frac{k_{s}}{k_{s}+k_{l s}}\right) \frac{x_{l s}}{\bar{x}_{s}} \hat{x}_{11}\right]=0
$$

If the state ignores any impacts expansion of its tax base has on local revenues $(\alpha=0)$ then,

as is the case with local governments, the state will choose to tax the entire base $\left(\bar{k}_{s}^{*}=0\right)$.

Less obvious is the case when $\alpha=1$ and the state fully considers the impact on local revenues when choosing of both its tax rate and tax base. The state faces a trade off when expanding its tax base - it lowers the marginal cost of funds associated with any state tax rate but also reduces local revenues. Intuitively, the gain in social welfare of an increase in a tax base, absent other distorting taxes, is equal to- $M R S \tau \hat{x}_{11}$. That the impact in (2.18) is $\left(M R S_{s}-1\right) D\left(\frac{x_{z}}{\bar{x}_{s}}-1\right)-M R S_{s} \tau_{s}^{*} \hat{x}_{11}$ reflects the fact that when the two tax bases partially overlap, the addition to the tax base of another commodity $\left(x_{l s}\right)$ is less than the average tax base per commodity in the existing base $\left(\bar{x}_{s}\right)$. However, in the Nash equilibrium, the local government will tax the entire base, making $k_{s}=0$. In this case then, it is clearly optimal for the state government to tax the entire base as $W_{k_{s}}^{s}=-\tau_{s}^{* 2} V_{y} M R S_{s} \hat{x}_{11}>0$. Some implications of (2.16) and (2.17) are summarized in the proposition below.

Proposition 3. Assume the local and state governments independently choose their tax bases.

a) In equilibrium both levels of government tax the entire tax.

b) When the state government maximizes social welfare $(\alpha=1)$ in equilibrium $M R S_{s}>$ $M R S_{l}$; when $\alpha<1$ the relationship between $M R S_{s}$ and $M R S_{l}$ is not obvious.

That the $M R S_{s}>M R S_{l}$ when the state government maximizes social welfare $(\alpha=1)$ is a result of the fact that the state government considers the impact its taxing decision have on local revenues while local governments do not consider the effects of their taxes on state 
revenues. The relationship between $M R S_{s}$ and $M R S_{l}$ can be obtained by subtracting the first order condition for the local tax rate, (2.11), from that of the state (2.14) to obtain

$$
M R S_{s}=\left[\frac{1+(1-\alpha) \tau_{l}^{*}\left(\hat{x}_{11}+\hat{x}_{21}\right)}{1+\tau_{s}^{*}\left(\hat{x}_{11}+\hat{x}_{21}\right)}\right] M R S_{l} .
$$

\section{Optimal Tax Base Division and Co-occupancy}

As shown in the preceding section, both levels of government will tax the entire tax base if given the option. Changes in the local governments' tax bases as well as their tax rates will generate fiscal externalities. Here I address the question of what is the social-welfare maximizing division of the tax base between the two levels of government. I first address the question of how the tax base should be divided if there is no co-occupancy. After deriving the optimal division of the tax base, the question of whether the state and local governments should share tax bases, that is, whether there should be any co-occupancy, is then addressed.

If the state government fully considers the impacts of its tax policy on local revenues $(\alpha=1)$, if it were also have the authority to determine the extent of both its and the local governments tax bases, the choices would be welfare-maximizing. However, if $\alpha<1$, the state government does not fully consider the impacts of its tax policy on local revenues. Then, in this case, if the state government were to determine the tax bases for both levels of government it would not choose the welfare-maximizing division. As I wish to investigate the welfare-maximizing division of the tax base in the case of $\alpha<1$ rather than the state government determining the tax base division, a third-party (federal government or "planner") chooses the tax bases to maximize social welfare.

In addition to having a third party choose the optimal division of the tax base, the timing of the division of the tax base, relative to the setting of the state and local tax rates, also needs to be determined. My focus will be on a Nash equilibrium in which the state and local governments choose their tax rates at the same time as the planner chooses the division of the tax base. In Section 3.3 I discuss a two-stage game in which the federal government chooses the division of the tax base in the first stage of the game and the state and local governments simultaneously set their tax rates in the second stage.

\subsection{The Optimal Division of the Tax Base}

The optimal division of the tax base in the absence of co-occupancy solves

$$
\underset{\bar{k}_{l}}{\operatorname{Max}} W\left[\tau_{l}, \tau_{s}, \bar{k}_{l}\right]=\int_{0}^{1} V(k) d k+U^{s}\left(g_{s}\left(\tau_{l}, \tau_{s}, \bar{k}_{l}\right)\right)+\alpha U^{l}\left(g_{l}\left(\tau_{l}, \tau_{s}, \bar{k}_{l}\right)\right)
$$


where, given no co-occupancy, $k_{l}=\bar{k}_{l}$ and $k_{s}=1-\bar{k}_{l}$. Then the optimal division of the tax base, $\bar{k}_{l}^{*}$, that satisfies the first order condition for (3.1) can be expressed as

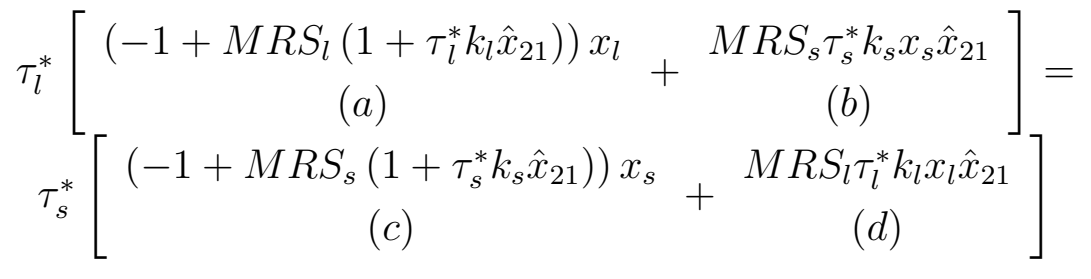

where, again, $\tau_{l}^{*}$ and $\tau_{s}^{*}$ are the equilibrium tax rates. Derivation of (3.2) and other equations as well as proofs of propositions in this section are found in Appendix A.3. The expansion of the local tax base and contraction of the state tax base directly increases local revenue by $\tau_{l} x_{l}$ and indirectly by affecting the price of $x\left(\bar{k}_{l}\right)$, now taxed at a rate of $\tau_{l}$ rather than $\tau_{s}$. As well, the tax has a direct impact through its impact on the price of $x\left(\bar{k}_{l}\right)$. These impacts of found in term (a) of (3.2). Term $(b)$ is the impact of adding $x\left(\bar{k}_{l}\right)$ to the local tax base on state tax revenues. Then the optimal division of the tax base must be such that the impact on utility of the expansion of the local tax base is exactly offset by the impact of the equal reduction of the state tax base, terms (c) and (d) of (3.2). Rearranging terms in (3.2) yields

$$
\left(M R S_{l}-1\right) \tau_{l}^{*} x_{l}-\left(M R S_{s}-1\right) \tau_{s}^{*} x_{s}+\quad\left(\tau_{l}^{*}-\tau_{s}^{*}\right)\left(M R S_{l} \tau_{l}^{*} k_{l} x_{l}+M R S_{s} \tau_{s}^{*} k_{s} x_{s}\right) \hat{x}_{21}=0
$$

Examination of equation (3.3) provides for additional characterization of the optimal division of the tax base. From (3.3) we can see that if commodities are substitutes $\left(\hat{x}_{21}>0\right)$ the sign of term (b) is the sign of $\tau_{l}-\tau_{s}$. Then if, for example, $\tau_{l}>\tau_{s}$ it must be the case that term (a) is negative, requiring $M R S_{l}<M R S_{s}$. If $\tau_{l}(.5)>(<) \tau_{s}(.5)$ then $\left.W_{\bar{k}_{l}}\right|_{\bar{k}_{l}=.5}>(<) 0$ and the optimal division of the tax base must be $\bar{k}_{l}^{*}>(<) .5$. With $\hat{x}_{21}>0$ and $\bar{k}_{l}^{*}>(<) .5(3.3)$ can only be satisfied when the optimal tax rates are $\tau_{l}^{*}>(<) \tau_{s}^{*}$.

When commodities are complements or $\alpha \neq 0$, the relationship between the relative tax rates and the relative MRS is indeterminate - with $\tau_{l}>\tau_{s}$ it is possible to have $M R S_{l}<$ $M R S_{s}$ or $M R S_{l}>M R S_{s}$ and satisfy (3.3). This being the case, it is possible for (3.3) to be satisfied with no obvious relationship between the equilibrium tax rates $\left(\tau_{l}^{*}, \tau_{s}^{*}\right)$, the associate MRS, and the relative tax rates when the base is evenly split.

Proposition 4. In the absence of co-occupancy, the optimal division $\left(\bar{k}_{l}^{*}\right)$ of the tax base can be characterized by the following:

a) If $\alpha=0$ and i) $\tau_{l}(.5)>(<) \tau_{s}(.5)$ then $\bar{k}_{l}^{*}>(<) .5$; ii) $\hat{x}_{21}>0$ and $\tau_{l}(.5)>(<) \tau_{s}(.5)$ 
then $\tau_{l}\left(\bar{k}_{l}^{*}\right)>(<) \tau_{s}\left(\bar{k}_{l}^{*}\right)$ and $M R S_{l}\left(\bar{k}_{l}^{*}\right)<(>) M R S_{s}\left(\bar{k}_{l}^{*}\right)$.b) If $\alpha=1$ and i) $\hat{x}_{21}>0$ and $\tau_{l}(.5) \geq \tau_{s}(.5)$ then $\bar{k}_{l}^{*}>.5$ and ; ii) $\hat{x}_{21}<0$ and $\tau_{l}(.5) \leq \tau_{s}(.5)$ then $\bar{k}_{l}^{*}<.5$; iii) $\hat{x}_{21}>0$ then $\tau_{l}\left(\bar{k}_{l}^{*}\right)<\tau_{s}\left(\bar{k}_{l}^{*}\right)$; and $\left.i v\right) \hat{x}_{21}<0$ then $\tau_{l}\left(\bar{k}_{l}^{*}\right)>\tau_{s}\left(\bar{k}_{l}^{*}\right)$.

c) $A t \bar{k}_{l}^{*}, \quad M R S_{l} \tau_{l}\left(\bar{k}_{l}^{*}\right) \neq M R S_{s} \tau_{s}\left(\bar{k}_{s}^{*}\right)$.

d) $A t \bar{k}_{l}^{*}:$ i) if $\hat{x}_{21}=0$, a (marginal) change in either the local or state tax rate has no impact on social welfare; ii) if $\hat{x}_{21}>(<) 0$ and $\alpha=0$, an increase (decrease) in the local or state tax rate will increase social welfare; iii) if $\hat{x}_{21}>(<) 0$, and $\alpha=1$ an increase (decrease) in the local tax rate will increase social welfare while an increase in the state tax rate will have no impact on social welfare.

Proof of the proposition is found in Appendix A.3.2. Part c) of the proposition, $M R S_{l} \tau_{l}\left(\bar{k}_{l}^{*}\right) \neq$ $M R S_{s} \tau_{s}\left(\bar{k}_{s}^{*}\right)$, is important when considering whether co-occupancy is optimal. Part $d$ ) provides relationships between the division of the tax base and the fiscal externality from increases in the tax rates. As suggested by the proposition, the division of the tax base will not eliminate the fiscal externalities associated with the two tax rates when commodities have non-zero cross-price elasticities. This can easily be seen by differentiating the social welfare function with respect to the tax rate of a single locality,

$$
W_{\tau_{l}}=\frac{1}{n} M R S_{s} \tau_{s}\left(1-\bar{k}_{l}^{*}\right) \bar{k}_{l}^{*} \hat{x}_{21}
$$

In the case of gross substitutes, it may change the fiscal externality from being negative with co-occupancy to being positive with no co-occupancy. This, in turn, means that taxes also change from being "too" high to being "too" low, that is, below the welfare maximizing rates.

\subsection{Optimal Co-Occupancy of Tax Bases}

That the tax rates and marginal rates of substitutions for the public services are not equal for the two levels of government and tax rate increases or decreases can enhance social welfare suggests at least the possibility that co-occupancy may be desirable. Below I consider the possibility of co-occupancy and under what conditions it may be socially optimal.

The problem facing the planner is

$$
\begin{gathered}
\operatorname{Maximize} \\
\bar{k}_{l}, \bar{k}_{s}
\end{gathered}\left(\bar{k}_{l}, \bar{k}_{s}, \tau_{s}, \tau_{l}\right)=\int_{0}^{1} V\left(q(k) d k+U^{s}\left(g_{s}\left(\bar{k}_{l}, \bar{k}_{s}, \tau_{s}, \tau_{l}\right)\right)+U^{l}\left(g_{l}\left(\bar{k}_{l}, \bar{k}_{s}, \tau_{s}, \tau_{l}\right)\right)\right.
$$


Then the first order conditions with the respect to the tax bases when $k_{l s}>0$ can be expressed as

$$
\begin{gathered}
\left(1-\bar{k}_{l}\right) W_{\bar{k}_{l}}=\left(1-\bar{k}_{l}\right) V_{y} \tau_{l}^{*} x_{l s}\left[\begin{array}{c}
-1+M R S_{l}\left(1+\tau_{l}^{*}\left(k_{l s}+k_{l}\right) \frac{\bar{x}_{l}}{x_{l s}} \hat{x}_{21}\right) \\
+M R S_{s} \tau_{s}^{*}\left(\hat{x}_{11}+\left(k_{s}+k_{l s}\right) \frac{\bar{x}_{s}}{x_{l s}} \hat{x}_{21}\right)
\end{array}\right]=0 \text { and } \\
\bar{k}_{s} W_{\bar{k}_{s}}=\bar{k}_{s} V_{y} \tau_{s}^{*} x_{l s}\left[\begin{array}{c}
-1+M R S_{s}\left(1+\tau_{s}^{*}\left(k_{l s}+k_{s}\right) \frac{\bar{x}_{s}}{x_{l s}} \hat{x}_{21}\right) \\
+ \\
+\operatorname{MR} S_{l} \tau_{l}^{*}\left(\hat{x}_{11}+\left(k_{l}+k_{l s}\right) \frac{\bar{x}_{l}}{x_{l s}} \hat{x}_{21}\right)
\end{array}\right]=0
\end{gathered}
$$

To evaluate the impact of an increase in the local tax base on social welfare when there is no co-occupancy $\left(\bar{k}_{l}=\bar{k}_{s}\right)$, we can subtract $\left.W_{\tau_{l}}^{l}\right|_{\tau_{l}^{*}}=0$ (2.11) from (3.6) and evaluate with $k_{l s}=0$ to obtain

$$
W_{\bar{k}_{l}}=\tau_{l}^{*} x_{l s}\left[\left(M R S_{l} \tau_{l}^{*}-M R S_{s} \tau_{s}^{*}\right)\left(-\hat{x}_{11}\right)+\left[M R S_{l} \tau_{l}^{*} k_{l}\left(\frac{x_{l}}{x_{l s}}-1\right)+M R S_{s} \tau_{s}^{*} k_{s} \frac{x_{s}}{x_{l s}}\right] \hat{x}_{21}\right] .
$$

Analogously, subtracting the first order condition for the state tax rate (2.14) from (2.17) and evaluating at $k_{l s}=0$ gives

$$
-\left.W_{\bar{k}_{s}}\right|_{k_{l s}=0}=\tau_{s}^{*} x_{l s}\left[\begin{array}{c}
\left(M R S_{s} \tau_{s}^{*}-M R S_{l} \tau_{l}^{*}\right)\left(-\hat{x}_{11}\right) \\
+\left[M R S_{s} \tau_{s}^{*} k_{s}\left(\frac{x_{s}}{x_{l s}}-1\right)+M R S_{l} \tau_{l}^{*}\left(k_{l} \frac{x_{l}}{x_{l s}}-\alpha k_{s} \frac{x_{l}}{x_{l s}}\right)\right] \hat{x}_{21}
\end{array}\right] .
$$

From (3.8) - (3.9), results about the optimal co-occupancy of the tax base can be obtained. These results are summarized in the proposition below.

Proposition 5. Let $\tau_{l}^{*}, \tau_{s}^{*}$, and $\bar{k}_{l}^{*}$ represent the values of the tax rates and the division of the tax base in the absence of co-occupancy that satisfy (2.11), (2.14), and (3.3). Then:

a) Necessary conditions for the optimal division of the tax base to be such that some share of it is tax by both levels of government (co-occupied) is that either (3.8) or (3.9) are positive.

b) If $\hat{x}_{21}>0$ either $\left.W_{\bar{k}_{l}}\right|_{k_{l s}=0}>0$ or $-\left.W_{\bar{k}_{s}}\right|_{k_{l s}=0}>0$ and it is optimal to co-occupy some share of the tax base.

c) If $\hat{x}_{21}<0$ then a sufficient condition for it not to be optimal to co-occupy the tax base is $\left(\tau_{l}^{*} x_{l s}-\tau_{s}^{*} x_{s}\right)+k_{s} \tau_{l}^{*} \widetilde{\tau}_{s}^{*} x_{s}\left(\frac{x_{l s}}{x_{s}}-1\right) \hat{x}_{21}<0$ and $\left(\tau_{s}^{*} x_{l s}-\tau_{l}^{*} x_{l}\right)+k_{l} \widetilde{\tau}_{l}^{*} \tau_{s}^{*} x_{l}\left(\frac{x_{l s}}{x_{l}}-1\right) \hat{x}_{21}<0$. d) Letting $\widetilde{K}_{l}$ and $\widetilde{K}_{s}$ denote the optimal division of the tax base. Then if if it optimal to have co-occupancy either: i) One or both governments will tax the entire base $\left(\widetilde{K}_{l}=\right.$ 1 and $\widetilde{K}_{s}=0\left(k_{l s}=1\right), \widetilde{K}_{l}=1$ and $\widetilde{K}_{s}>0\left(k_{l s}<1, k_{l}>0, k_{s}=0\right)$, or $\widetilde{K}_{l}<1$ and $\widetilde{K}_{s}=0$ $\left(k_{l s}<1, k_{l}=0, k_{s}>0\right)$. or ii) each government taxes only part of the base $\left(0<\widetilde{K}_{s}<\widetilde{K}_{l}<\right.$ $1)$. In this case, at the optimal division of the tax base, 


$$
M R S_{l}+M R S_{s} \tau_{s} \hat{x}_{11}=M R S_{s}+M R S_{l} \tau_{l} \hat{x}_{11} .
$$

Proof of part c) is found in Appendix A.3.3 with remainder of the Proposition discussed below. That it is optimal to have co-occupancy when the commodities are substitutes $\left(\hat{x}_{21}>0\right)$ (Part b) follows immediately from (3.8) and (3.9) and part c) of Proposition 4 - either the first term of (3.8) or (3.9) must be positive. As the second term of both expressions, primarily composed of the impact on the segment of the other level's tax base that is not co-occupied, must be positive then one or both of (3.8) and (3.9) must be positive. Part $d$ ), specifically the condition to be satisfied when each government only taxes part of the base, follows from (3.6) and (3.7) - for an interior solution to satisfy both conditions (3.10) must be satisfied. Note that if $M R S_{s}=M R S_{l}$ and $\tau_{l}=\tau_{s}$ (3.10) is satisfied. More generally, (3.10) suggests that the "indirect" effects of a marginal expansions of the two governments base, the change in tax revenue from the existing bases for both governments cancel each other out and the direct effects of expansion, the increase in the benefits from the public services for the expanding base $\left(M R S_{l}, M R S_{s}\right)$ and the decrease in benefits for the other base $\left(M R S_{l} \tau_{l}, M R S_{s} \tau_{s}\right)$ are the only relevant factors.

To provide some further intuition, consider evaluating (3.6) at the optimal division of the tax base in the case of the state and local tax rates being equal and, by (3.3), $M R S_{l}=M R S_{s}$. Then $M R S_{s} \tau_{s}-M R S_{l} \tau_{l}=0$ and (3.8) and (3.9) become

$$
\begin{gathered}
\left.W_{\bar{k}_{l}}\right|_{k_{l}^{*}}=\left[M R S_{l} \tau_{l}^{*} k_{l}\left(\frac{x_{l}}{x_{l s}}-1\right)+M R S_{s} \tau_{s}^{*} k_{s} \frac{x_{s}}{x_{l s}}\right] \hat{x}_{21} \text { and } \\
-\left.W_{\bar{k}_{s}}\right|_{k_{l}^{*}}=\left[M R S_{s} \tau_{s}^{*} k_{s}\left(\frac{x_{s}}{x_{l s}}-1\right)+M R S_{l} \tau_{l}^{*}\left(k_{l} \frac{x_{l}}{x_{l s}}-\alpha k_{s} \frac{x_{l}}{x_{l s}}\right)\right] \hat{x}_{21} .
\end{gathered}
$$

As discussed, the state and local tax rates will not be equal at the optimal division the base if $\hat{x}_{21} \neq 0$. The difference in the two tax rates accounts for the first terms in (3.8) and (3.9) in which there are additional welfare gains to expanding the base for which the "direct" impact $(M R S \tau)$ is greatest. Intuitively, (3.11) is the welfare impact of increases

(decreases) in tax revenue in the segments of both the state and local tax base that are not co-occupied if $\hat{x}_{21}>(<) 0$. This increase (decrease) in tax revenue is relative to that obtained by expanding the local tax base while reducing the state tax base by an equal amount. An analogous argument can be made for expansion of the state tax base and (3.12).

\subsection{Optimal Division and Co-Occupancy with Leadership}

In Sections 3.1 and 3.2 the determination of the optimal tax bases is determined in the context of Nash equilibrium in a simultaneous game. In this section, I briefly discuss how 
the results in these sections might change if rather than having simultaneous determination of both the tax bases and tax rates, they are determined in a two-stage game and show that the results are qualitatively unchanged.

In the first stage of the game tax bases are chosen by the federal government and in the second stage tax rates are determined in a Nash game among the state and local governments. The tax rates determined in the second stage are characterized by (2.11)and (2.14) and are functions of the state and local tax bases with $k_{l s}=0$ in the absence of co-occupancy. Then in the first stage, the optimal division again solves (3.1) but this case the state and local tax rates are functions of the division of the tax base, $\tau_{l}\left(\bar{k}_{l}\right)$ and $\tau_{s}\left(\bar{k}_{l}\right)$. Then the first order condition is now given by

$$
\begin{gathered}
\tau_{l}^{*}\left(-1+M R S_{l}\left(1+\tau_{l}^{*} k_{l} \hat{x}_{21}\right)\right) x_{l}+M R S_{s} \tau_{s}^{*} \tau_{l}^{*} k_{s} x_{s} \hat{x}_{21}\left(1+\hat{\tau}_{l}\right)= \\
\tau_{s}^{*}\left(-1+M R S_{s}\left(1+\tau_{s}^{*} k_{s} \hat{x}_{21}\right)\right) x_{s}+M R S_{l} \tau_{s}^{*} \tau_{l}^{*} k_{l} x_{l} \hat{x}_{21}\left(1+(1-\alpha) \hat{\tau}_{s}\right) .
\end{gathered}
$$

where $\hat{\tau}_{j}=\frac{1}{\tau_{j}} \frac{d \tau_{j}}{d \bar{k}_{l}}, j=l, s$. As the local tax rate is chosen to maximize (2.4) without regard to the impact on state revenues, the only impact that any change in the local tax rate has on welfare is through its impact on state revenues. Analogously, the impact of changes in the state tax rate depend on any impacts depend on the impact on local revenues and whether the state welfare function includes local public services as an argument $(\alpha \neq 0)$. If $\alpha=1$ then there is no impact of changes in the state tax on welfare. Further, if $\left|\hat{\tau}_{j}\right|<$ $1, j=l, s$, that is, the change in the tax base leads to less than a 100 percent change in the tax rates, then the impacts of expansion of the local tax base on state tax revenues $\left(M R S_{s} \tau_{s}^{*} \tau_{l}^{*} k_{s} x_{s} \hat{x}_{21}\left(1+\hat{\tau}_{l}\right)\right)$ and the impact of contraction of the state tax base on local revenues $\left(M R S_{l} \tau_{s}^{*} \tau_{l}^{*} k_{l} x_{l} \hat{x}_{21}\left(1+(1-\alpha) \hat{\tau}_{s}\right)\right)$ are qualitatively the same (same sign) as in the Nash equilibrium.

Then, as in the Nash equilibrium, consider an expansion of the local tax base and no contraction of the state tax base in the absence of co-occupancy $\left(k_{l s}=0\right)$. Differentiating (3.1) with respect to $\bar{k}_{l}$ gives

$W_{\bar{k}_{l}}=\tau_{l}^{*} x_{l s}\left[\begin{array}{c}\left(M R S_{l} \tau_{l}^{*}-M R S_{s} \tau_{s}^{*}\right)\left(-\hat{x}_{11}\right) \\ \left.+\left[M R S_{l} \tau_{l}^{*} k_{l}\left(x_{l}\left(\frac{1}{x_{l s}}+(1-\alpha) \frac{\tau_{s}^{*}}{\tau_{l}^{*}} \hat{\tau}_{s}\right)-1\right)+M R S_{s} \tau_{s}^{*} k_{s} x_{s}\left(\frac{1}{x_{l s}}+\tau_{l}^{*} \hat{\tau}_{l}\right)\right] \hat{x}_{21}\right] .\end{array}\right.$

Analogously, subtracting the first order condition for the state tax rate (2.14) from (2.17) and evaluating at $k_{l s}=0$ gives 
$-\left.W_{\bar{k}_{s}}\right|_{k_{l s}=0}=\tau_{s}^{*} x_{l s}\left[\begin{array}{c}\left(M R S_{s} \tau_{s}^{*}-M R S_{l} \tau_{l}^{*}\right)\left(-\hat{x}_{11}\right) \\ +\left[M R S_{s} \tau_{s}^{*} k_{s} x_{s}\left(\frac{1}{x_{l s}}+\tau_{l}^{*} \hat{\tau}_{l}\right)+M R S_{l} \tau_{l}^{*} \frac{x_{l}}{x_{l s}}\left(k_{l}-\alpha k_{s}+(1-\alpha) \tau_{s}^{*} \hat{\tau}_{s}\right)\right] \hat{x}_{21}\end{array}\right]$

Then if, as seems reasonable, the terms $\left[\begin{array}{c}M R S_{l} \tau_{l}^{*} k_{l}\left(x_{l}\left(\frac{1}{x_{l s}}+(1-\alpha) \frac{\tau_{s}^{*}}{\tau_{l}^{*}} \hat{\tau}_{s}\right)-1\right) \\ +M R S_{s} \tau_{s}^{*} k_{s} x_{s}\left(\frac{1}{x_{l s}}+\tau_{l}^{*} \hat{\tau}_{l}\right)\end{array}\right]$ in (3.14) and $\left[\begin{array}{c}M R S_{s} \tau_{s}^{*} k_{s} x_{s}\left(\frac{1}{x_{l s}}+\tau_{l}^{*} \hat{\tau}_{l}\right)+ \\ M R S_{l} \tau_{l}^{*} \frac{x_{l}}{x_{l s}}\left(k_{l}-\alpha k_{s}+(1-\alpha) \tau_{s}^{*} \hat{\tau}_{s}\right)\end{array}\right]$ in (3.15) are positive then with $\hat{x}_{21}>0$ it will be optimal to have co-occupancy. As with the case when the tax base and tax rates are simultaneously determined, when $\hat{x}_{21}<0$ co-occupancy may not be optimal.

\subsection{Optimal Co-Occupancy with Differential State Taxation}

Thus far the analysis has been restricted to considering uniform tax rates across both tax bases. I now consider the possibility that the state government can set different rates on the shared tax base $\left(k_{l s}\right)$ and the base that it alone taxes $\left(k_{s}\right)$. For the state government to have an incentive to set (substantially) different tax rates on the two segments of its base, it must be the case that $\alpha \neq 0$ - it considers the impact of its tax policies on local revenues. For simplicity, let $\alpha=1 .^{7}$ Then as $\alpha=1$, the choice of the tax bases can be considered that of the state government. Then the objective of the state government is

$$
\begin{gathered}
\text { Maximize } \\
\tau_{s}^{l s}, \tau_{s}^{s}, \bar{k}_{l}, \bar{k}_{s}
\end{gathered}\left(\bar{k}_{l}, \bar{k}_{s}, \tau_{s}^{l s}, \tau_{s}^{s}, \tau_{l}\right)=\begin{gathered}
\int_{0}^{1} V\left(q(k) d k+U^{s}\left(g_{s}\left(\bar{k}_{l}, \bar{k}_{s}, \tau_{s}^{l s}, \tau_{s}^{s}, \tau_{l}\right)\right)\right. \\
+U^{l}\left(g_{l}\left(\bar{k}_{l}, \bar{k}_{s}, \tau_{s}^{l s}, \tau_{s}^{s}, \tau_{l}\right)\right)
\end{gathered}
$$

where $\tau_{s}^{l s}$ is the state rate on the co-occupied segment and $\tau_{s}^{s}$ is the state rate on the segment it alone taxes. Then the first order conditions for both tax rates are given by

$$
W_{\tau_{s}^{s}}=\begin{gathered}
-1+M R S_{s}\left[1+\tau_{s}^{s}\left(\hat{x}_{11}+k_{s} \hat{x}_{21}\right)\right] \\
+M R S \tau_{s}^{l s} k_{l s} \frac{x_{l s}}{x_{s}} \hat{x}_{21}+M R S_{l} \tau_{l}\left(k_{l}+k_{l s}\right) \frac{\bar{x}_{l}}{x_{s}} \bar{x}_{21}
\end{gathered}=0
$$

and

$$
W_{\tau_{s}^{l s}}=\begin{gathered}
-1+M R S_{s}\left[1+\tau_{s}^{l s}\left(\hat{x}_{11}+k_{l s} \hat{x}_{21}\right)\right] \\
+M R S_{s} \tau_{s}^{s} k_{s} \frac{x_{s}}{x_{l s}} \hat{x}_{21}+M R S_{l} \tau_{l}\left(\hat{x}_{11}+\left(k_{l}+k_{l s}\right) \frac{\bar{x}_{l}}{x_{l s}} \hat{x}_{21}\right)
\end{gathered}=0 .
$$

In considering the optimal tax base, I assume that there is overlap in the two bases $\left(k_{l s}>0\right)$.

\footnotetext{
${ }^{7}$ That the optimal tax rates are identical across the shared and unshared segments of the tax bases when $\alpha=0$ is an artifact of the assumption of constant elasticities. In the absence of this assumption, different optimal tax rates might be expected but not of the magnitude of differences that occur when $\alpha=1$.
} 
Then an increase in $\bar{k}_{l}$ means a reduction in the base only taxed by the state $\left(k_{s}\right)$ and a decrease in $\bar{k}_{s}$ means a reduction in the base only taxed by the localities $\left(k_{l}\right)$. Then the optimal tax bases are determined by

$$
\left(1-\bar{k}_{l}\right) W_{\bar{k}_{l}}=\left(1-\bar{k}_{l}\right)\left[\begin{array}{c}
{\left[\left(M R S_{l}-1\right) \tau_{l}+\left(M R S_{s}-1\right) \tau_{s}^{l s}\right] x_{l s}-\left(M R S_{s}-1\right) \tau_{s}^{s} x_{s}+} \\
{\left[M R S_{l} \tau_{l}\left(k_{l}+k_{l s}\right) \bar{x}_{l}+M R S_{s}\left(\tau_{s}^{l s} k_{l s} x_{l s}+\tau_{s}^{s} k_{s} x_{s}\right)\right] \hat{x}_{21}\left(\tau_{l}+\tau_{s}^{l s}-\tau_{s}^{s}\right)}
\end{array}\right]=0
$$

and

$-\bar{k}_{s} W_{\bar{k}_{s}}=\left(1-\bar{k}_{s}\right)\left[\begin{array}{c}{\left[\left(M R S_{l}-1\right) \tau_{l}+\left(M R S_{s}-1\right) \tau_{s}^{l s}\right] x_{l s}-\left(M R S_{l}-1\right) \tau_{l} x_{l}+} \\ {\left[M R S_{l} \tau_{l}\left(k_{l}+k_{l s}\right) \bar{x}_{l}+M R S_{s}\left(\tau_{s}^{l s} k_{l s} x_{l s}+\tau_{s}^{s} k_{s} x_{s}\right)\right] \hat{x}_{21} \tau_{s}^{l s}}\end{array}\right]=0$.

Consider a possible solution with $M R S_{s}=M R S_{l} \equiv M R S$ and $\tau_{l}+\tau_{s}^{l s}=\tau_{s}^{s}$. In this case, both (3.17) and (3.18) are satisfied only if $\bar{k}_{s}=0,\left(k_{l}=0\right)$ - the state taxes the entire base. As well, (3.19) will be satisfied with equality regardless of the division of the tax base. Then when $M R S_{s}=M R S_{l} \equiv M R S$ and $\tau_{l}+\tau_{s}^{l s}=\tau_{s}^{s}$, (3.20) becomes

$$
-\bar{k}_{s} W_{\bar{k}_{s}}=\left(1-\bar{k}_{s}\right)\left[(M R S-1)\left[\left(\tau_{l}+\tau_{s}^{l s}\right) x_{l s}-\tau_{l} x_{l}\right]+M R S\left(\tau_{l}+\tau_{s}^{l s}\right) \hat{x}_{21} \tau_{s}^{l s}\right]
$$

Then with $\left(\tau_{l}+\tau_{s}^{l s}\right) x_{l s}-\tau_{l} x_{l}>(<) 0$ when $\tau_{s}^{l s}>(<) 0$, for $-W_{\bar{k}_{s}}>0$ (and the state taxes the entire base), it must be the case that when commodities are substitutes (complements) $\left(\hat{x}_{21}>(<) 0\right)$ the state tax on the co-occupied segment of the tax base is positive (negative).

Thus two solutions appear possible: 1) the local government does not tax the entire base $\left(\bar{k}_{l}<1\right)$ and $M R S_{l}=M R S_{s}$, and $\tau_{s}^{l s}+\tau_{l}=\tau_{s}^{s}$; and 2) both the state and local governments tax the entire base $\left(\bar{k}_{l}=1\right)$ with $M R S_{l}>M R S_{s}$. However, to satisfy the first order conditions for both the state (3.18) and the local tax rates (2.11) in the second solution it must be the case that $M R S_{s}>M R S_{l}$. Thus a contradiction and only the first solution is feasible.

When $M R S_{l}=M R S_{s}$ and $\tau_{s}^{l s}+\tau_{l}=\tau_{s}^{s}$ we can subtract the first order condition for the local tax rate (2.11) from (3.20) to obtain

$$
\tau_{s}^{l s}\left(\hat{x}_{11}+k_{l s} \hat{x}_{21}\right)+\tau_{s}^{s} k_{s} \hat{x}_{21}=0 .
$$

Equation (3.22) states that the state government chooses its tax rates and the tax base that the local government can tax $\left(k_{l s}\right)$ so that the local tax rate generates no fiscal externality. These results are summarized in the following proposition:

Proposition 6. If $\alpha=1$ and the state can set different tax rates on the shared based $\left(k_{l s}\right)$ and the base it alone taxes $\left(k_{s}\right)$, its optimal tax rates and the division of the tax base are 
such that:

a) The state will tax the entire base $\left(\bar{k}_{s}=0\right)$ and localities will only tax some share of the base $\left(\bar{k}_{l}<1\right)$;

b) $M R S_{l}=M R S_{s}$;

c) The combined state and local tax on the co-occupied share of the tax base equals the state tax rate on the share of the base it alone taxes $\tau_{s}^{l s}+\tau_{l}=\tau_{s}^{s}$;

d) The local tax rate generates no fiscal externality, that is, $\tau_{s}^{l s}\left(\hat{x}_{11}+k_{l s} \hat{x}_{21}\right)+\tau_{s}^{s} k_{s} \hat{x}_{21}=0$; and

e) The state tax rate on the co-occupied segment is greater (less) than zero $\left(\tau_{s}^{l s}>(<) 0\right)$ if cross-price elasticities are greater (less) than zero $\left(\hat{x}_{21}>(<) 0\right)$.

While Hoyt (2001) considers the overlapping tax bases and the possibility of negative tax rates (subsidies), it was in the context of exogenously-determined tax bases. In that case, whether the state government applies a positive (negative) tax rate on a shared tax base was determined by whether $M R S_{l}>(<) M R S_{s}$. In this case, the state government is choosing the extent of the overlap in tax base the state applies a positive (negative) tax rate on the shared based when commodities are substitutes (complements).

\section{Optimal Assignment with Horizontal Externalities}

While the framework for my analysis has been couched in terms of multiple localities, local tax policies have only impacted state tax revenues and not those of other localities. That is, it is a framework with vertical externalities but with an absence of horizontal externalities.

A number of studies have examined the implications of the existence of both horizontal and vertical externalities. Keen and Kotsogiannis (2002), for example, considers a standard model of capital taxation competition (Wilson (1986); Zodrow and Mieszkowkski (1986)) with two levels of government (state and federal) with a focus on whether decentrallydetermined tax rates are inefficiently high or low. As discussed in more detail later, I incorporate fiscal externalities into the model developed in Section 2.1 following a different approach with the externality generated by cross-border shopping. I also introduce some heterogeneity into the nature of the commodities in the tax base, allowing the extent of the horizontal fiscal externality to vary among commodities. My objectives in this section are two-fold. As before, I consider the optimal division of the tax base and whether cooccupancy is optimal. Second, with this heterogeneity among commodities, the issue which commodities should be assigned to which tax base, local or state, can be addressed as well. This is, in essence, the issue of assignment discussed, for example, by Musgrave (1983). 


\subsection{A Simple Model of Cross-Border Shopping}

A natural way to incorporate horizontal externalities into the framework developed in Section 2.1 is to allow for cross-border shopping. I follow the approach of Nielsen (2001) and Agrawal (2012) to generate this cross-border shopping though I focus on the case of symmetric jurisdictions (localities). To generate vertical fiscal externalities, unlike Nielsen (2001) and Agrawal (2012), I need to assume elastic demands for the commodities. As well, the cross-border shopping costs are assumed to differ among commodities. To incorporate this into the model, let the $J$ localities be distributed in a circle with an interval of one unit between each locality as illustrated in Figure 3. Then a length of $1 / 2$ on each side of the locality center (CBD) is defined as the locality. The population is distributed uniformly with density of unity.

As in Nielsen (2001) and Agrawal (2012) purchases of commodities occur at the location of residence or, if purchased in another locality, at the border between the locality of residence and that of purchase. As mentioned, I allow for the cost to vary with the commodity - for some commodities both total and marginal costs of the cross-border shopping are higher. Obvious examples might be perishable groceries in which purchases of inventories is not possible in contrast to dry goods in which inventories are possible. Then let $c_{k} m$ be the travel cost for an individual living a distance $m$ from the border. Then the commodity with the lowest with absolute and marginal travel cost is $k=0$ and the commodity with the highest travel cost is $k=K$. Then the total cost of commodity $k$ purchased in locality $j-1$ by an individual in locality $j$ living $m$ from the border with locality $j$ is

$$
q\left(k, m_{j, j-1}\right)=1+\tau_{j-1}+\tau_{s}+c_{k} m .
$$

with an analogous condition for the price of commodity $k$ purchased in locality $j+1$ for a resident of locality $j$ residing $m$ from the border with locality $j+1 q\left(k, m_{j, j+1}\right)$. Then the boundaries for purchases of commodity $k$ made in locality $j$ are given by

$$
\underline{m}_{j}^{k}=-\frac{1}{2}+\frac{\tau_{j}-\tau_{j-1}}{c_{k}} \text { and } \bar{m}_{j}^{k}=\frac{1}{2}+\frac{\tau_{j+1}-\tau_{j}}{c_{k}} .
$$

with the number of shoppers for commodity $k$ in locality $j$ given by

$$
N_{j}(k)=1+\frac{\tau_{j+1}+\tau_{j-1}-2 \tau_{j}}{c_{k}}
$$

While the shopping costs are assumed to vary among commodities, in the symmetric equilibrium with $\tau_{j+1}=\tau_{j}=\tau_{j-1}=\tau_{l}^{*} \forall j$ the number of shoppers for each commodity $k$ in each locality $j$ will be 1 . I also assume that for commodities in the same tax base the quantity demanded is the same and is referred to by $x_{l}, x_{s}$, and $x_{l s}$ for the local, state, and shared 
bases as before.

The expression for the local government budget is complicated. It depends on the tax rates in the two adjacent localities and, unlike, the framework developed in Sections 2 and 3 not simply the lengths of the tax intervals (number of commodities taxed) as the commodities differ in responses to taxes in other localities. An expression for it can be found in Appendix A.4. As our interest is in analyzing equilibrium policies, I consider the impact of a local tax increase when all localities set the same tax rates and, therefore, $\underline{m}_{j}^{k}=-\frac{1}{2}$ and $\bar{m}_{j}^{k}=\frac{1}{2}$ for all localities $j$ and commodities $k$. Then differentiating the local budget constraint with respect to $\tau_{j}$ and letting $j=l$ gives

$$
\frac{d g_{l}}{d \tau_{l}}=X_{l}\left[1+\tau_{l}\left(\hat{x}_{11}+\left(k_{l}+k_{l s}\right) \hat{x}_{21}+\widehat{N}_{\tau_{l}}\right)\right]
$$

where $X_{l}$ is the local tax base $a$ nd $\widehat{N}_{\tau_{l}} \tau_{l} X_{l}<0$ is the change in the tax base due to crossborder shopping. ${ }^{8}$ Then in the symmetric Nash equilibrium among localities, the optimal local tax satisfies the condition

$$
M R S_{l}=\frac{1}{\left[1+\tau_{l}^{*}\left(\hat{x}_{11}+\left(k_{l s}+k_{l}\right) \hat{x}_{21}+\widehat{N}_{\tau_{l}}\right)\right]} .
$$

Then (4.5) is identical to (2.11) with the exception of the term $\tau_{l} X_{l} \widehat{N}_{\tau_{l}}$ where, as mentioned, this term represents the loss in tax revenue to the locality due to shoppers leaving the locality to shop in other localities.

\subsection{Optimal Division and Co-Occupancy of the Tax Base with Cross-Border Shopping}

To evaluate the trade offs between the horizontal and vertical externalities associated with the local taxes, consider the impacts of a uniform increase in the equilibrium local tax rate across localities and commodities within the local and shared tax based. Then differentiating social welfare with respect to $\tau_{l}$ and applying (4.5) gives

\footnotetext{
${ }^{8}$ The impact of an increase in the local tax rate on total purchases and, therefore, tax revenue depends on the mix of commodities in the tax local tax base. If, for example, the local tax base was continuous from $\left[0, \bar{k}_{l}\right]$ then $\widehat{N}_{\tau_{l}}=-\frac{1}{X_{l}}\left[\int_{0}^{\bar{k}_{s}} \frac{x\left(k, q=1+\tau_{l}\right)}{c_{k}} d k+\int_{\bar{k}_{s}}^{\bar{k}_{l}} \frac{x\left(k, q=1+\tau_{l}+\tau_{s}\right)}{c_{k}} d k\right]$
} 


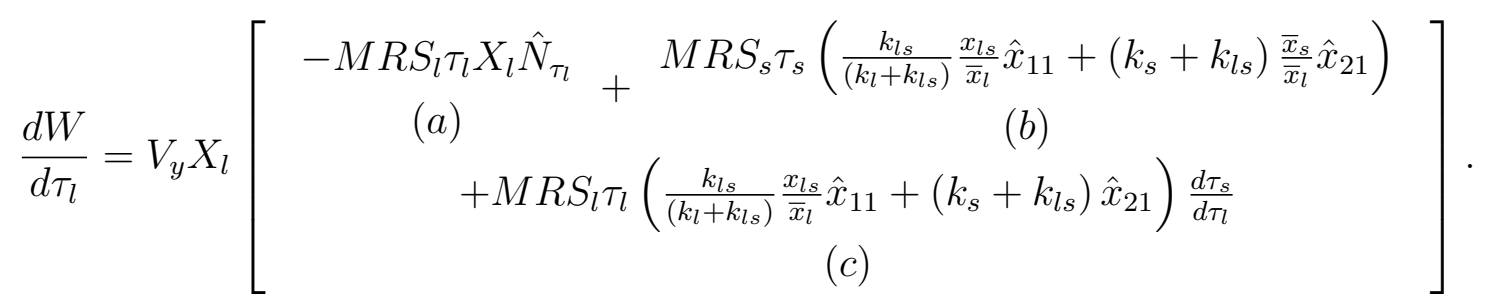

Term (a) of (4.6) reflects the increase in social welfare from "too low" of local tax rates due to the horizontal externality while term (b) reflects the vertical externality, the impact on state tax revenues and the level of the state public service, analogous to (2.12). ${ }^{9}$ Term (c) reflects the impact of any response in the state tax rate on local tax revenues and the local public service. Under the reasonable assumption that the direct effect of the increase in the local tax rate on local public services (term (a)) outweighs the indirect effects through resulting changes in the state tax $(\operatorname{term}(c))$ then if commodities are substitutes $\left(\hat{x}_{21}>0\right)$ in the absence of any overlap in tax bases $\left(k_{l s}=0\right)$ term $(b)$ is positive and increases in the local tax rate unambiguously increase welfare. If there is co-occupancy $\left(k_{l s}>0\right)$ or commodities are complements $\left(\hat{x}_{21}<0\right)$ then the sign of $(4.6)$ is ambiguous. Then if $\hat{x}_{21}>0$ it must be the case that the social-welfare maximizing local tax rate $\frac{d W}{d \tau_{l}}=0$ only occurs when $k_{l s}>0$ and will never be obtained with $\hat{x}_{21}<0$.

The extent of how much cross-border shopping $\left(\hat{N}_{\tau_{l}}\right)$ increases when a locality's tax rate increases depends on the mix of commodities in its tax base. Then as the equilibrium local and state tax rates depend on the mix of commodities base and not simply the extent of the local tax base so does social welfare. As shown in Appendix A.4 if there is no overlap in the tax base $\left(k_{l s}=0\right)$ then $\frac{d \tau_{l}}{d \hat{N}_{\tau_{l}}}>0$ - the substitution of a more elastic (with respect to cross-border shopping) commodity with one with a less elastic demand will increase the equilibrium local tax rate. Then if commodities are substitutes $\left(\hat{x}_{21}>0\right)$ by $(4.6)$ in the absence of co-occupancy local governments should tax those commodities with the lowest cross-border shopping costs.

The case when commodities are complements is somewhat more complicated. Unlike the case with substitutes, as discussed earlier, with complements the horizontal and vertical externalities are of opposite signs and the assignment of the local tax base is not obvious.

The optimal division of the tax base continues to be described by (3.2) and (3.3) with

${ }^{9}$ Term (a) appears because while (4.4) is $\frac{d g_{j}}{d \tau_{j}}$ when a single locality $j$ increases its tax rate in equilibrium, when all localities uniformly increase tax rates, $\frac{d g_{l}}{d \tau_{l}} \mid=X_{l}\left[1+\tau_{l}\left(\hat{x}_{11}+\left(k_{l}+k_{l s}\right) \hat{x}_{21}\right)\right]$. Then by the envelope theorem, $\left(M R S_{l}\left[1+\tau_{l}\left(\hat{x}_{11}+\left(k_{l}+k_{l s}\right) \hat{x}_{21}+\widehat{N}_{\tau_{l}}\right)\right]-1\right) X_{l}=0$ meaning that $\left(M R S_{l}\left[1+\tau_{l}\left(\hat{x}_{11}+\left(k_{l}+k_{l s}\right) \hat{x}_{21}\right)\right]-1\right) X_{l}=-M R S_{l} \tau_{l} X_{l} \hat{N}_{\tau_{l}}$. 
modifications to allow for the heterogeneity in the local tax base arising from cross-border shopping. Adding a commodity to the local tax base and removing it from the state tax base means that differences in local tax rates will induce cross-border shopping. However, as in equilibrium all local governments will have the same tax rates, there will be no impact on the tax base due to cross-border shopping.

However, when evaluating the optimal division of the tax base at the optimally-chosen tax rates for the local governments (4.5) and the state (2.14) government with cross-border shopping, the characterization of the optimal division of the tax base is no longer analogous. With cross-border shopping, the optimal division can be characterized by

$$
\left.W_{\bar{k}_{l}}\right|_{\bar{k}_{s}=1-\bar{k}_{l}}=\begin{gathered}
\left(M R S_{l} \tau_{l}^{* 2} x_{l}-M R S_{s} \tau_{s}^{* 2} x_{s}\right)\left(-\hat{x}_{11}\right)+M R S_{l} \tau_{l}^{* 2} x_{l}\left(-\widehat{N}_{\tau_{l}}\right) \\
+\tau_{l}^{*} \tau_{s}^{*}\left(M R S_{s} k_{s} x_{s}-(1-\alpha) M R S_{l} k_{l} x_{l}\right) \hat{x}_{21}
\end{gathered}=0
$$

The substantive difference between (4.7) and the analogous condition in the absence of cross-border shopping (A.26) is the term $M R S_{l} \tau_{l}^{*^{2}} x_{l}\left(-\widehat{N}_{\tau_{l}}\right)$. While it is difficult to directly compare the division of the tax base with and without cross-border shopping, (4.7) has the term $M R S_{l} \tau_{l}^{* 2} x_{l}\left(-\widehat{N}_{\tau_{l}}\right)$ that is not present in the first order condition obtain in the absence of cross-border shopping, (3.3). That this term is positive suggests that cross-border shopping, by reducing the tax rates set by local governments increases the gains to expanding the local tax base at the expense of the state tax base.

To evaluate the conditions under which co-occupancy is welfare-improving, evaluate the welfare impact of an increase in the local base (3.6) at with $\bar{k}_{l}^{*}$ and at the tax rate that satisfies (4.5) gives

$$
\left.W_{\bar{k}_{l}}\right|_{k_{l s}=0}=\tau_{l}^{*} x_{l s}\left[\left(M R S_{l} \tau_{l}^{*}-M R S_{s} \tau_{s}^{*}\right)\left(-\hat{x}_{11}\right)+M R S_{l} \tau_{l}^{*}\left(-\widehat{N}_{\tau_{l}}\right)+M R S_{s} \tau_{l}^{*} \tau_{s}^{*} k_{s} \hat{x}_{21}\right] .
$$

The impact of an increase in the state tax base is unchanged and characterized by (3.9). Then, as in the case without co-occupancy, it must be the case that with $\hat{x}_{21}>0$, cooccupancy is optimal. In this case, there is a more significant impact on welfare from an increase in the local tax base because of the detrimental impact of cross-border shopping on local tax rates and welfare, making it more likely that an expansion of the local tax base is optimal even if $\hat{x}_{21}<0$.

Proposition 7. With the existence of cross-border shopping across localities as characterized by (4.1) - (4.3), the welfare-maximizing assignment of the tax base satisfies:

a) If $\hat{x}_{21}>0$ local governments tax those commodities with the lowest cross border shopping 
costs $\left(c_{k}\right)$;

b) The optimal division of the tax bases satisfies (4.7) in the absence of co-occupancy;

c) If (4.8) or (3.9) are positive then it is optimal to have co-occupancy; if $\hat{x}_{21}>0$ then either (4.8) or (3.9) is positive and it is optimal to have co-occupancy.

\section{Concluding Comments}

The conventional wisdom suggests that separate tax bases for different levels of government is preferred to reduce the extent of vertical externalities and the over-provision of public services associated with the vertical externality. However, most previous studies have not considered the impacts of tax rates across revenues sources, that is, across tax bases. Specifically, how changes in tax rates in one base may influence revenues from other tax bases that are not shared. To the extent that these tax bases are on commodities that are substitutes, a positive, not negative, fiscal externality is generated.

With a strict division of the tax base in which there is no co-occupancy I show that when there are non-zero cross-price elasticities, it is not possible to have both equal tax rates by both governments and equal marginal rates of substitution for their public services, the (second) best solution.

While the focus of the literature on vertical fiscal externalities has been on the externalities generated by choices of the tax rate, here I also consider the externalities generated by choices of tax base, specifically considering the case of endogenous choices of tax bases. Not surprisingly, if given the choice, both levels of government will tax the entire base.

That equality in rates and valuation of public services is in general not possible in the absence of co-occupancy means the optimality of co-occupancy cannot be ruled out a prior. Here I show that under some conditions, specifically differences in the optimal tax rates in the absence of co-occupancy and underlying cross-price elasticities, co-occupancy might be optimal. I also show that if the higher-level government (state) can differentially tax (or subsidize) the shared tax base and the base it alone taxes and can tax the entire base, (second-best) optimality is achieved.

Finally, I extend the model to allow for horizontal fiscal externalities arising from crossborder shopping and find similar results about when co-occupancy is desirable as well as results regarding which commodities should be included in the two tax bases. 


\section{References}

Agrawal, David R. 2012. "The Tax Gradient: Do Local Sales Taxes Reduce Tax Differentials at State Borders?" Working Paper, University of Georgia.

Bird, Richard M. 2000. "Rethinking Subnational Taxes: A New Look at Tax Assignment." Tax Notes International, 8: 2069-2096.

Bird, Richard M., and Pierre-Pacal Gendron. 2000. "CVAT, VIVAT, and Dual VAT: Vertical "Sharing" and Interstate Trade." International Tax and PUblic Finance, 7: 753761.

Bird, Richard M., and Pierre-Pascal Gendron. 1998. "Dual VATs and Cross-border Trade: Two Problems, One Solution?" International Tax and PUblic Finance, 5(429-442).

Boadway, Robin, and Micahel Keen. 1996. "Efficiency and the Optimal Direction of Federal-state Transfers." International Tax and Public Finance, 3: 137-155.

Boadway, Robin, Katherine Cuff, and Maurice Marchand. 2003. "Equalization and the Decentralization of Revenue-Raising in a Federation." Journal of Public Economic Theory, 5(2): 201-228.

Boadway, Robin, Maurice Marchand, and Michael Vigneault. 1998. "The Consequences of Overlapping Tax Bases for Redistribution and Public Spending in a Federation." Journal of Public Economics, 68(453-478).

Dahlby, Bev. 1996. "Fiscal Externalities and the Design of Intergovernmental Grants." International Tax and Public Finance, 3(3): 397-412.

Dahlby, Bev. 2001. "Taxing Choice: Issues in the Assignment of Taxes in Federations." International Social Science Journal, 93-100.

Dahlby, Bev. 2008. The Marginal Cost of Public Funds. Cambridge, MA:The MIT Press.

Dahlby, Bev, and Leonard S. Wilson. 2003. "Vertical Fiscal Externalities in a Federation." Journal of Public Economics, 87: 917-930.

Dahlby, Bev, Jack Mintz, and Sam Wilson. 2000. "The Deductibility of Provincial Business Taxes in a Federation with Vertical Fiscal Externalities." The Canadian Journal of Economics, 33(3): 677-694. 
Dixit, Avinash K., and Joseph E. Stiglitz. 1977. "Monopolistic Competition and Optmum Product Diversity." American Economic Review, 67(3): 287-308.

Flochel, Laurent, and Thierry Madies. 2002. "Interjurisdictional Tax Competition in a Federal System of Overlapping Revenue Maximizing Governments." International Tax and Public Finance, 9: 121-141.

Flowers, Marylin. 1988. "Shared Tax Sources in a Leviathan Model of Federation." Public Finance Quarterly, 16: 67-77.

Haufler, Andreas, and Christoph Lulfesmann. 2015. "Reforming an Asymmetric Union: On the Virtues of Dual Tier Capital Taxation." Journal of Public Economics, 125: $116-127$.

Hoyt, William. 2001. "Tax Policy Coordination, Vertical Externalities, and Optimal Taxation in a System of Hierarchical Governments." Journal of Urban Economics, 50: 491-516.

Johnson, William R. 1988. "Income Redistribution in a Federal System." American Economic Review, 78: 570-573.

Keen, Michael. 1995. "Pursing Leviathan: Fiscal Federalism and International Tax Competition." Working Paper, University of Essex, Colchester, England.

Keen, Michael. 1998. "Vertical Tax Externalities in the Theory of Fiscal Federalism." IMF Staff Papers, 45(3): 454-485.

Keen, Michael. 2000. "VIVAT, CVAT, and All That: New Forms of Value-added Tax for Federal Systems." Canadian Tax Journal, 48.

Keen, Michael, and Christos Kotsogiannis. 2002. "Does Federalism Lead to Excessively High Taxes?" American Economic Review, 92(1): 363-370.

Keen, Michael, and Christos Kotsogiannis. 2003. "Leviathan and Capital Tax Competition in Federations." Journal of Public Economic Theory, 5(2): 177-199.

Keen, Michael, and Christos Kotsogiannis. 2004. "Tax Competition in Federations and the Welfare Consequences of Decentralization." Journal of Urban Economics, 56: 397-407.

Keen, Michael, and Stephen Smith. 2000. "Viva VIVAT!" International Tax and Public Finance, 6: 741-751.

Kotsogiannis, Christos, and Pascalis Raimondos. 2015. "Tax Base Co-occupation and Pareto Efficiency." Working Paper, University of Exeter. 
McLure, Charles E. 2001. "The Tax Assignment Problem: Ruminations on How Theory and Practice Depend on History." National Tax Journal, 54(2): 339-364.

Musgrave, Richard A. 1983. "Who Should Tax, Where, and What?" Canberra, Australia:Australian National University Press.

Musgrave, Richard A., and Peggy A. Musgrave. 1989. Public Finance in Theory and Practice. . 5 ed., New York, NY:McGraw-Hill.

Nielsen, Søren Bo. 2001. "A Simple Model of Commodity Taxation and Cross-Border Shopping." The Scandinavian Journal of Economics, 103(4): 599-623.

Oates, Wallace E. 1994. Federalism and Government Finance. Cambridge, MA:Harvard University Press.

Wilson, John D. 1986. "A Theory of Interregional Tax Competition." Journal of Urban Economics, 19(3): 296-315.

Wilson, John D. 1989. "On the Optimal Tax Base for Commodity Taxation." American Economic Review, 79(5): 1196-1206.

Wilson, John D., and Eckhard Janeba. 2005. "Decentralization and International Tax Competition." Journal of Public Economics, 89(7): 1211-1229.

Wrede, Matthias. 1996. "Vertical and Horizontal Tax Competition: Will Uncoordinated Leviathans End Up on the Wrong Side of the Laffer Curve?" FinanzArchiv, 53(3-4): 461479 .

Wrede, Matthias. 2000. "Shared Tax Sources and Public Expenditures." International Tax and Public Finance, 7: 163-175.

Yitzhaki, Shlomo. 1979. "A Note on Optimal Taxation and Administration Costs." American Economic Review, 69: 475-480.

Zodrow, George R., and Peter Mieszkowkski. 1986. "Pigou, Tiebout, Property Taxation, and the Underprovision of Local Public Goods." Journal of Urban Economics, 19: $356-370$. 
Table 1: Percent of Total Own-Source by Tax Base, State, Local, and Federal, $2012^{1}$

\begin{tabular}{|l||l||l||l|}
\hline Tax Base & Local & State & Federal \\
\hline \hline Property & 30.9 & 0.8 & \\
\hline General Sales & 5.5 & 15.6 & \\
\hline Excise/Selective Sales & 3.1 & 11.9 & 3.4 \\
\hline Individual Income & 3.1 & 26.7 & 44.0 \\
\hline Corporate Income & 0.8 & 3.9 & 9.1 \\
\hline Motor Vehicle/Other & 2.8 & 7.4 & 6.4 \\
\hline Social Insurance/Retirement & 7.4 & 29.6 & 37.1 \\
\hline
\end{tabular}

1. From Government Finances Statistics (http://www.census.gov/govs/financegen/index.html) 
Figure 1: A Vertical Externality in a Single Market

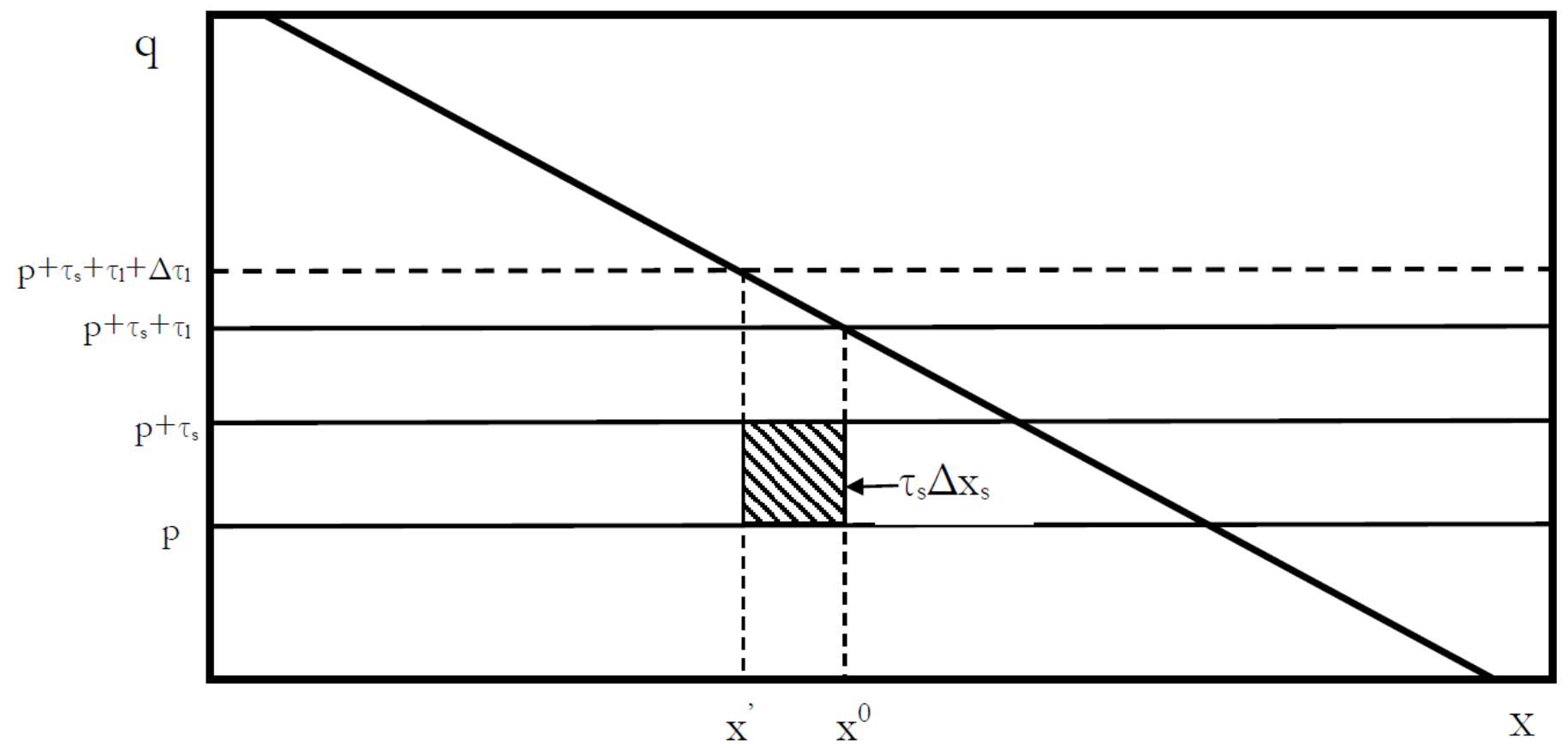


Figure 2: The Division of the Tax Base
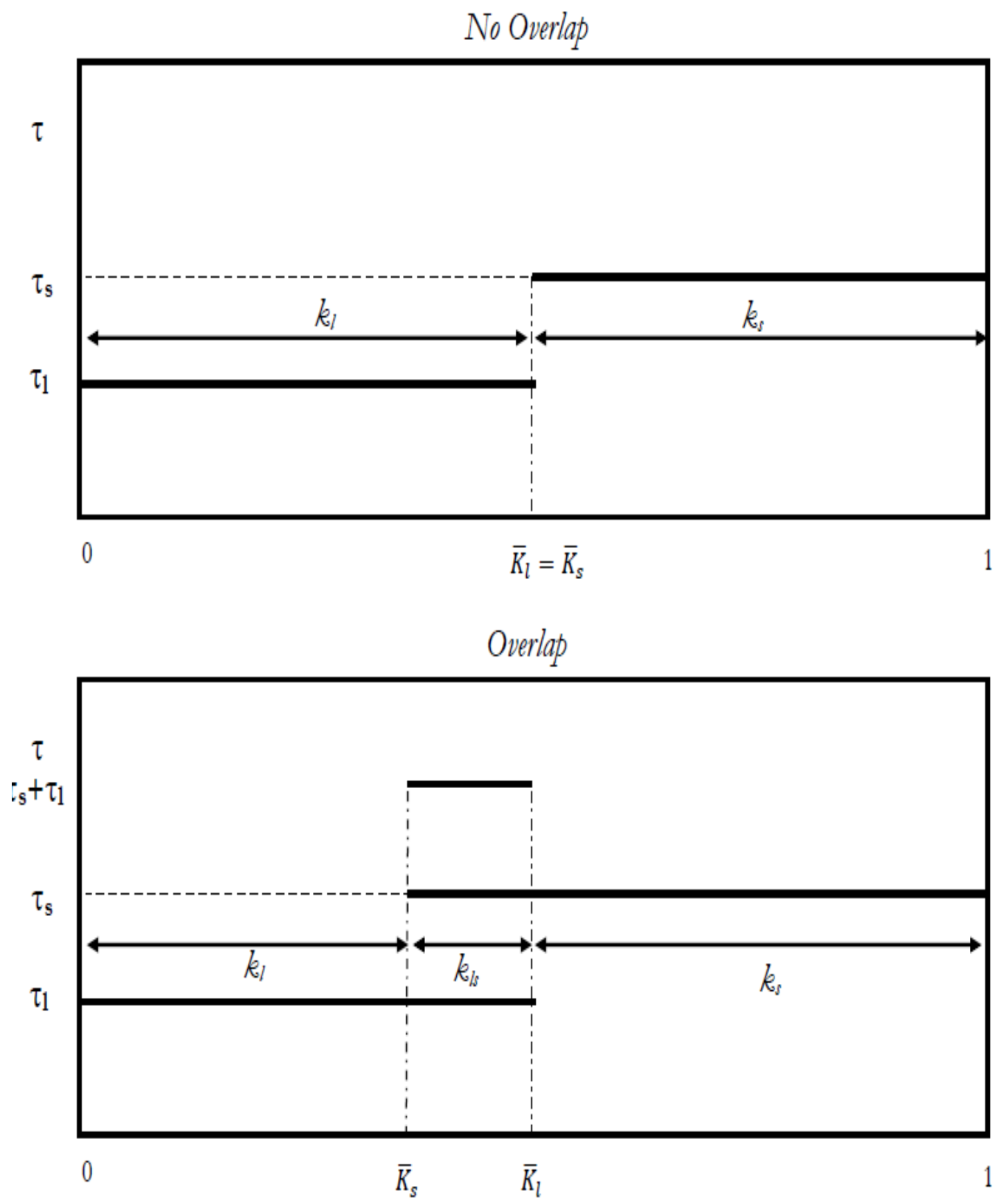
Figure 3: Locations of Local Governments with Cross-Border Shopping

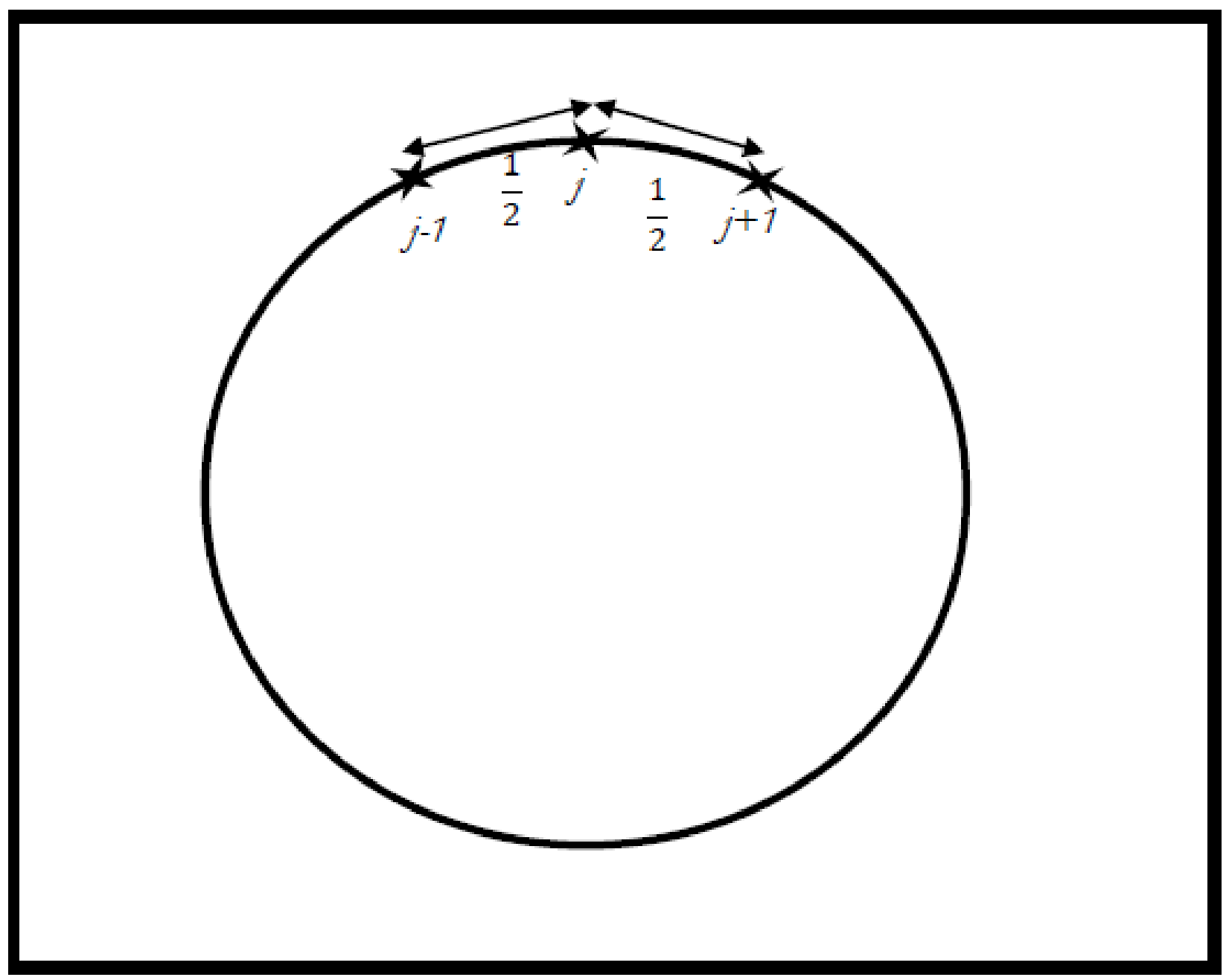




\section{A Appendix (Online)}

\section{A.1 Tax Rates and Bases}

\section{A.1.1 Definitions of Tax Bases}

The state budget constraint is given by

$$
g_{s}=\begin{gathered}
\int \bar{k}_{s} x\left(q(k)=1+\tau_{s}, Q\right) d k \equiv k_{s} x_{s}, \bar{k}_{l}<\bar{k}_{s} \\
\int_{\bar{k}_{s}}^{\bar{k}_{l}} x\left(q(k)=1+\tau_{1}+\tau_{s}, Q\right) d k+\int_{\bar{k}_{l}}^{1} x\left(q(k)=1+\tau_{s}, Q\right) d k \equiv k_{l s} x_{l s}+k_{s} x_{s}, \bar{k}_{l}>\bar{k}_{s}
\end{gathered}
$$

and local budget constraint is given by

$$
g_{l}=\begin{gathered}
\int_{0}^{\bar{k}_{l}} x\left(q(k)=1+\tau_{l}, Q\right) d k \equiv k_{l} x_{l}, \bar{k}_{l}<\bar{k}_{s} \\
\int_{0}^{\bar{k}_{s}} x\left(q(k)=1+\tau_{1}, Q\right) d k+\int_{\bar{k}_{s}}^{\bar{k}_{l}} x\left(q(k)=1+\tau_{l}+\tau_{s}, Q\right) d k \equiv k_{l s} x_{l s}+k_{l} x_{l}, \bar{k}_{l}>\bar{k}_{s}
\end{gathered} .
$$

\section{A.1.2 The Impact of Taxes on Government Budget Constraints}

Impacts of Taxes on the Price Index (Q) Differentiating the price index with respect to the tax rates gives

$$
\frac{d Q}{d \tau_{l}}=\begin{gathered}
k_{l}, \quad \bar{k}_{l}<\bar{k}_{s} \\
k_{l}+k_{l s}, \bar{k}_{l}>\bar{k}_{s}
\end{gathered} \text { and } \frac{d Q}{d \tau_{s}}=\begin{gathered}
k_{s}, \quad \bar{k}_{l}<\bar{k}_{s} \\
k_{s}+k_{l s}, \bar{k}_{l}>\bar{k}_{s}
\end{gathered}
$$

and differentiating it with respect to the tax bases gives

$$
\frac{d Q}{d \bar{k}_{l}}=\tau_{l},\left.\quad \frac{d Q}{d \bar{k}_{l}}\right|_{\bar{k}_{s}=1-\bar{k}_{l}}=\tau_{l}-\tau_{s}, \text { and } \frac{d Q}{d \bar{k}_{s}}=-\tau_{s}
$$

Impacts of Tax Rate Increases Then differentiating the local government budget (A.2) with respect to $\tau_{l}$ for $\bar{k}_{l}>\bar{k}_{s}$ gives

$$
\begin{gathered}
\frac{d g_{l}}{d \tau_{l}}=\left[\begin{array}{c}
\int_{0}^{\bar{k}_{s}} x\left(q(k)=1+\tau_{l}, Q\right) d k+\int_{\bar{k}_{s}}^{\bar{k}_{l}} x\left(q(k)=1+\tau_{l}+\tau_{s}, Q\right) d k+ \\
\tau_{l}\left[\int_{0}^{\bar{k}_{s}} \frac{\partial x\left(q(k)=1+\tau_{l}, Q\right)}{\partial q(k)} \frac{d q(k)}{d \tau_{l}} d k+\int_{0}^{\bar{k}_{s}} \frac{\partial x\left(q(k)=1+\tau_{l}, Q\right)}{\partial Q} \frac{d Q}{d \tau_{l}} d k\right]+ \\
\tau_{l}\left[\int_{\bar{k}_{s}}^{\bar{k}_{l}} \frac{\partial x\left(q(k)=1+\tau_{l}+\tau_{s}, Q\right)}{\partial q(k)} \frac{d q(k)}{d \tau_{l}} d k+\int_{\bar{k}_{s}}^{\bar{k}_{l}} \frac{\partial x\left(q(k)=1+\tau_{l}+\tau_{s}\right)}{\partial Q} \frac{d Q}{d \tau_{l}} d k\right]
\end{array}\right] \\
=k_{l} x_{l}+k_{l s} x_{l s}+\tau_{l}\left[\begin{array}{c}
k_{l} x_{l} \frac{x_{11}^{l}}{x_{l}}+k_{l s} x_{l s} \frac{x_{11}^{l s}}{x_{l s}}+k_{l}^{2} x_{l} \frac{x_{21}^{l}}{x_{l}} \\
+k_{l s}^{2} x_{l s} \frac{x_{21}^{l s}}{x_{l s}}+k_{l} k_{l s} x_{l} \frac{x_{21}^{l}}{x_{l}}+k_{l} k_{l s} x_{l s} \frac{x_{21}^{l s}}{x_{l s}}
\end{array}\right] \\
=k_{l} x_{l}+k_{l s} x_{l s}+\tau_{l}\left[\hat{x}_{11}+\left(k_{l}+k_{l s}\right) \hat{x}_{21}\right]
\end{gathered}
$$


if it is assumed that $\frac{x_{11}^{s}}{x_{s}}=\frac{x_{11}^{l s}}{x_{l s}}=\frac{x_{11}^{l}}{x_{l}} \equiv \widehat{x}_{11}$ and $\frac{x_{21}^{s}}{x_{s}}=\frac{x_{21}^{l s}}{x_{l s}}=\frac{x_{21}^{s}}{x_{s}}=\widehat{x}_{21}$

The impact of the local tax increase on state tax base is

$$
\begin{gathered}
\frac{d g_{s}}{d \tau_{l}}=\tau_{s}\left[\begin{array}{c}
\int_{\bar{k}_{s}}^{\bar{k}_{l}} \frac{\partial x\left(q(k)=1+\tau_{l}+\tau_{s}, Q\right)}{\partial q(k)} d k+\int_{\bar{k}_{s}}^{\bar{k}_{l}} \frac{\partial x\left(q(k)=1+\tau_{l}+\tau_{s}, Q\right)}{\partial Q} \frac{d Q}{d \tau_{l}} d k+ \\
+\int_{\bar{k} l}^{1} \frac{\partial x\left(q(k)=1+\tau_{s}, Q\right)}{\partial Q} \frac{d Q}{d \tau_{l}} d k
\end{array}\right] \\
=\tau_{s}\left(k_{l s} x_{l s} \frac{x_{11}^{l s}}{x_{l s}}+k_{l} k_{l s} x_{l s} \frac{x_{21}^{l s}}{x_{l s}}+k_{l s}^{2} x_{l s} \frac{x_{21}^{l s}}{x_{l s}}+k_{l} k_{s} x_{s} \frac{x_{21}^{s}}{x_{s}}+k_{l s} k_{s} x_{s} \frac{x_{21}^{s}}{x_{s}}\right) \\
=\tau_{s} X_{s}\left(\frac{k_{l s}}{\left(k_{s}+k_{l s}\right)} \frac{x_{l s}}{\bar{x}_{s}} \hat{x}_{11}+\left(k_{l}+k_{l s}\right) \hat{x}_{21}\right)
\end{gathered}
$$

with analogous derivations for $\frac{d g_{s}}{d \tau_{s}}$ and $\frac{d g_{l}}{d \tau_{s}}$.

The impacts of state tax increases on the state and local budgets can be derived analogously to those for the local tax increases and are summarized in (2.6).

Impact of Tax Base Increases Case 1: No overlap $\left(\bar{k}_{s}<\bar{k}_{l}\right)$

For the impact on the local tax revenue, differentiate (A.2)with respect to $\bar{k}_{l}$ :

$$
\begin{gathered}
\frac{d g_{l}}{d \bar{k}_{l}}=\frac{d\left[\tau_{l} \int_{0}^{\bar{k}_{l}} x(k) d k\right]}{d \bar{k}_{l}}=\tau_{l}\left[\int_{0}^{\bar{k}_{l}} \frac{\partial x(k)}{\partial Q} d k \frac{\partial Q}{\partial \bar{k}_{l}}+x\left(\bar{k}_{l}, q=1+\tau_{l}\right)\right] \\
=\tau_{l}\left[x_{l}+\tau_{l} k_{l} x_{21}^{l}\right]=\tau_{l} x_{l}\left[1+\tau_{l} k_{l} \hat{x}_{21}\right]
\end{gathered}
$$

For the impact on state tax revenue differentiate (A.1),

$$
\begin{gathered}
\frac{d g_{s}}{d \bar{k}_{l}}=\frac{d\left[\tau_{s} \int_{\bar{k}_{s}}^{1} x(k) d k\right]}{d \bar{k}_{l}}=\tau_{s} \int_{\bar{k}_{s}}^{1} \frac{\partial x(k)}{\partial Q} d k \frac{\partial Q}{\partial \bar{k}_{l}}=\tau_{l} \tau_{s} k_{s} x_{21}^{s} \\
=\tau_{l} \tau_{s} k_{s} x_{s} \frac{x_{21}}{x_{s}}=\tau_{l} \tau_{s} k_{s} x_{s} \widehat{x}_{21}
\end{gathered}
$$

Case 2: Overlap $\left(\bar{k}_{s}>\bar{k}_{l}\right)$

For the impact on the local tax revenue, differentiate (A.2) with respect to $\bar{k}_{l}$,

$$
\begin{array}{r}
\frac{d\left[\tau_{l}\left(\int_{0}^{\bar{k}_{s}} x(k) d k+\int_{\bar{k}_{s}}^{\bar{k}_{l}} x(k) d k\right)\right]}{d g_{l}}=\tau_{l}\left[x\left(\bar{k}_{l}, q=1+\tau_{l}+\tau_{s}\right)+\left(\int_{0}^{\bar{k}_{s}} \frac{\partial x(k)}{\partial Q} \frac{\partial Q}{\partial \bar{k}_{l}} d k+\int_{\bar{k}_{s}} \frac{\bar{k}_{l}}{\partial Q} \frac{\partial x(k)}{\partial Q} \frac{\partial Q}{\partial \bar{k}_{l}}\right)\right] \\
=\tau_{l}\left[x_{l s}+\tau_{l}\left(k_{l} x_{21}^{l}+k_{l s} x_{21}^{l s}\right)\right]=\tau_{l}\left[x_{l s}+\tau_{l}\left(k_{l} x_{l} \frac{x_{21}^{l}}{x_{l}}+k_{l s} x_{l s} \frac{x_{21}^{l s}}{x_{l s}}\right)\right] \\
=\tau_{l}\left[x_{l s}+\tau_{l}\left(k_{l} x_{l}+k_{l s} x_{l s}\right) \widehat{x}_{21}\right]=\tau_{l} \bar{x}_{l}\left[\frac{x_{l s}}{\bar{x}_{l}}+\left(k_{l}+k_{l s}\right) \hat{x}_{21}\right]
\end{array}
$$

For the impact on state tax revenue differentiate (A.1), 


$$
\begin{aligned}
& \frac{d\left[\tau_{s}\left(\int_{\bar{k}_{s}}^{\bar{k}_{l}} x(k) d k+\int_{\bar{k}_{1}}^{1} x(k) d k\right)\right]}{d \bar{k}_{l}}=\tau_{s}\left[\begin{array}{c}
-x\left(\bar{k}_{l}, q=1+\tau_{s}\right)+x\left(\bar{k}_{l}, q=1+\tau_{l}+\tau_{s}\right) \\
+\left(\int_{\bar{k}_{s}}^{\bar{k}_{l}} \frac{\partial x(k)}{\partial Q} \frac{\partial Q}{\partial \bar{k}_{l}} d k+\int_{\bar{k}_{1}}^{1} \frac{\partial x(k)}{\partial Q} \frac{\partial Q}{\partial \bar{k}_{l}} d\right)
\end{array}\right] \\
& \frac{d g_{s}}{d \bar{k}_{l}}=\quad=\tau_{s}\left[-x_{s}+x_{l s}+\tau_{l}\left(k_{s} x_{21}^{s}+k_{l s} x_{21}^{l s}\right)\right] \approx \tau_{l} \tau_{s}\left[x_{s} \frac{x_{11}^{s}}{x_{s}}+k_{s} x_{s} \frac{x_{21}^{s}}{x_{s}}+k_{l s} x_{l s} \frac{x_{21}^{l s}}{x_{l s}}\right] \\
& \approx \tau_{l} \tau_{s}\left[x_{s} \widehat{x}_{11}+\left(k_{s} x_{s}+k_{l s} x_{l s}\right) \widehat{x}_{21}\right]=\tau_{l} \tau_{s} \bar{x}_{s}\left[\frac{x_{s}}{\bar{x}_{s}} \hat{x}_{11}+\left(k_{s}+k_{l s}\right) \hat{x}_{21}\right]
\end{aligned}
$$

The impacts of an increase in the state tax base are analogous to those of an increase in the local tax base.

Finally, consider the impact of an (equal) increase in the local tax base and decrease in the state tax base when there is no overlap

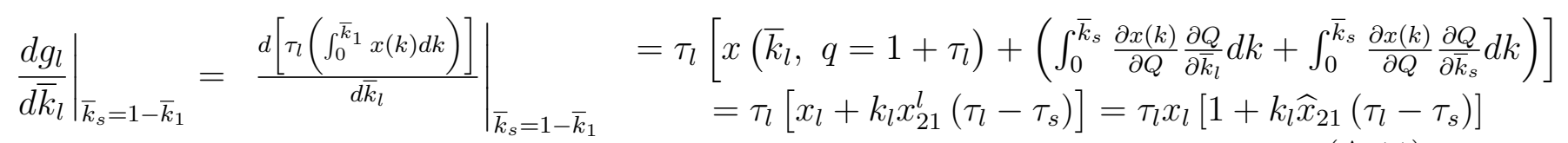

and

$$
\left.\frac{d g_{s}}{d \bar{k}_{l}}\right|_{\bar{k}_{s}=1-\bar{k}_{1}}=\left.\frac{d\left[\tau_{s}\left(\int_{\bar{k}_{s}}^{1} x(k) d k\right)\right]}{d \bar{k}_{l}}\right|_{\bar{k}_{s}=1-\bar{k}_{1}}=\tau_{s}\left[-x\left(\bar{k}_{s}, q=1+\tau_{s}\right)+\left(\int_{\bar{k}_{s}}^{1} \frac{\partial x(k)}{\partial Q} \frac{\partial Q}{\partial \bar{k}_{l}} d k+\int_{\bar{k}_{s}}^{1} \frac{\partial x(k)}{\partial Q} \frac{\partial Q}{\partial \bar{k}_{s}} d k\right)\right]
$$

\section{A.2 Derivations from Sections $2.2-2.4$}

\section{A.2.1 Derivations from Section 2.2}

Differentiating (2.8) with respect to $\tau_{s}$ yields

$$
W_{\tau_{s}}=\int_{\bar{k}_{s}}^{1} \frac{\partial V(k)}{\partial q(k)} \frac{d q(k)}{d \tau_{s}} d k+\int_{0}^{1} \frac{\partial V(k)}{\partial Q} \frac{d Q}{d \tau_{s}} d k+U_{g_{l}} \frac{d g_{l}}{d \tau_{s}}+U_{g_{s}} \frac{d g_{s}}{d \tau_{s}}=0
$$

where $V_{j_{l}}=\frac{\partial V}{\partial g_{j}}$. Then from Roy's identity we have $\frac{\partial V}{\partial q(k)}=-V_{y} x(k)$. Then $\int_{\bar{k}_{s}}^{1} \frac{\partial V}{\partial q(k)} d k=$ $-V_{y} \int_{\bar{k}_{s}}^{1} \frac{\partial x(k)}{\partial q(k)} d k=-V_{y}\left(k_{s} x_{s}+k_{l s} x_{l s}\right)$ where $V_{y}=\frac{\partial V}{\partial y}$. From (A.3) $\frac{d Q}{d \tau_{s}}=k_{s}+k_{l s}$. Then letting $M R S_{l}=\frac{U_{g_{l}}}{V_{y}}$ and $M R S_{s}=\frac{U_{g_{s}}}{V_{y}}$ and applying (2.6) to substitute for $\frac{d g_{l}}{d \tau_{s}}$ and $\frac{d g_{s}}{d \tau_{s}}$ yields (2.9).

\section{A.2.2 Derivations for Section 2.3}

\section{State and Local Tax Rates}

Differentiating (2.4) with respect to $\tau_{l}$ gives 


$$
W_{\tau_{l}}^{l}=\int_{0}^{\bar{k}_{l}} \frac{\partial V(k)}{\partial q(k)} \frac{d q(k)}{d \tau_{l}} d k+\int_{0}^{1} \frac{\partial V(k)}{\partial Q} \frac{d Q}{d \tau_{l}} d k+V_{g_{l}} \frac{d g_{l}}{d \tau_{l}}=0 .
$$

Again, from Roy's identity we have $\frac{\partial V}{\partial q(k)}=-V_{y} x(k)$. Then $\int_{0}^{\bar{k}_{l}} \frac{\partial V}{\partial q(k)} d k=-V_{y}\left(k_{l} x_{l}+k_{l s} x_{l s}\right)$.

From (A.3) $\frac{d Q}{d \tau_{s}}=k_{l}+k_{l s}$. Then letting $M R S_{l}=\frac{V_{g_{l}}}{V_{y}}$ and using applying (2.6) to substitute for $\frac{d g_{l}}{d \tau_{s}}$ and $\frac{d g_{s}}{d \tau_{s}}$ yields (2.11). Note that the first order condition for the state tax policy (2.14) is identical to that for the central government (2.9) when $\alpha=1$ and, in general, only differs from it by the term $M R S_{l} \tau_{l}\left(X_{l s} \hat{x}_{11}+X_{l} \hat{x}_{21}\right)$ being multiplied by $\alpha$.

\section{Proof of Proposition 2}

Below parts c) and d) are derived; parts a) and b) follow directly from (2.12) and (2.15). For part c, from (2.11) and (2.14) with $\alpha=0$ that if

$$
M R S_{s}=\frac{1}{\left[1+\tau_{s}^{*}\left(\hat{x}_{11}+\left(k_{s}+k_{l s}\right) \hat{x}_{21}\right)\right]}>(<) \frac{1}{\left[1+\tau_{l}^{*}\left(\hat{x}_{11}+\left(k_{l}+k_{l s}\right) \hat{x}_{21}\right)\right]}=M R S_{l}
$$

then cross-multiplying yields the expression in Part c.i). That $M R S_{s}>1$ and $M R S_{l}>1$ follows from that fact that $\left(\hat{x}_{11}+\left(k_{s}+k_{l s}\right) \hat{x}_{21}\right)<1$ and $\left(\hat{x}_{11}+\left(k_{l}+k_{l s}\right) \hat{x}_{21}\right)<1$ making the denominators for the expressions in (A.15 both less than one. For part d), using (2.11) in (2.14) gives

$$
M R S_{s}=\frac{1}{D_{s}}-\frac{\alpha \tau_{l}^{*}\left[\frac{X_{l}}{X_{s}}\right]\left[\frac{k_{l s}}{\left(k_{l s}+k_{l}\right)} \frac{x_{l s}}{\bar{x}_{l}} \hat{x}_{11}+\left(k_{l}+k_{l s}\right) \hat{x}_{21}\right]}{D_{l} D_{s}}>(<) \frac{1}{D_{l}}=M R S_{l}
$$

where $D_{s}=1+\tau_{s}^{*}\left(\hat{x}_{11}+\left(k_{s}+k_{l s}\right) \hat{x}_{21}\right)$ and $D_{l}=1+\tau_{l}^{*}\left(\hat{x}_{11}+\left(k_{s}+k_{l s}\right) \hat{x}_{21}\right)$. Then we obtain the expression in d.i) by multiplying (A.16) by $D_{s} D_{l}$. Part d.ii) can be seen from inspection of the expression for $M R S_{s}$ in (A.16). The first term, $\frac{1}{D_{s}}>1$; however, the second term $\frac{\alpha \tau_{l}^{*}\left[\frac{X_{l}}{X_{s}}\right]\left[\frac{k_{l s}}{\left(k_{l s}+k_{l}\right)} \frac{x_{l s}}{\bar{x}_{l}} \hat{x}_{11}+\left(k_{l}+k_{l s}\right) \hat{x}_{21}\right]}{D_{l} D_{s}}>(<) 0$.

\section{A.2.3 Derivations for Section 2.4}

\section{Local Tax Base}

Differentiating (2.4) with respect to its tax base, $\bar{k}_{l}$ gives

$$
\left(1-\bar{k}_{l}\right) W_{\bar{k}_{l}}^{l}=\left(1-\bar{k}_{l}\right)\left[\frac{d \int_{0}^{\bar{k}_{l}} V(k) d k}{d \bar{k}_{l}}+\frac{\partial U^{l}}{\partial g_{l}} \frac{d g_{l}}{d \bar{k}_{l}}\right]=0 .
$$


From the envelope theorem, $\frac{d \int_{0}^{\bar{k}_{l}} V(x(k)) d k}{d \bar{k}_{l}}=V_{y} \tau_{l} x_{l}$ if $\bar{k}_{l}<\bar{k}_{s}$ and if $\bar{k}_{l}>\bar{k}_{s} \frac{d \int_{0}^{\bar{k}_{l}} V(x(k)) d k}{d \bar{k}_{l}}=$ $V_{y} \tau_{l} x_{l s}$. In both cases $\frac{d Q}{d \bar{k}_{l}}=\tau_{l}$. Then substituting for $\frac{d g_{l}}{d \bar{k}_{l}}$ in (A.17) using (2.7) yields (2.16). Considering the case when $k_{l s}>0$ multiply $\left(k_{l s}+k_{l}\right)$

$$
W_{\bar{k}_{l}}^{l}=\tau_{l}\left[\left(M R S_{l}-1\right)\left(k_{l s}+k_{l}\right) x_{l s}+M R S_{l} \tau_{l}\left(k_{l s}+k_{l}\right)\left(k_{l s} x_{21}^{l s}+k_{l} x_{21}^{l}\right)\right]
$$

Then subtracting (A.14) from (A.18) gives

$$
W_{\bar{k}_{l}}^{l}=\tau_{l}\left[\left(M R S_{l}-1\right)\left[\left(k_{l s}+k_{l}\right) x_{l s}-\left(k_{l s} x_{l s}+k_{l} x_{l}\right)\right]-M R S_{l} \tau_{l}\left(k_{l s} x_{11}^{l s}+k_{l} x_{11}^{l}\right)\right] .
$$

Then using $x_{l s}-x_{l} \approx \tau_{l} x_{11}^{l}$ gives

$$
W_{\bar{k}_{l}}^{l} \approx \tau_{l}^{2}\left[M R S_{l} k_{l s} x_{l s}+k_{l} x_{l}\right]\left(-\hat{x}_{11}\right)>0
$$

\section{State Tax Base}

Analogous to the first order condition for the local tax base we have

$$
W_{\bar{k}_{s}}^{s}=\bar{k}_{s}\left[\frac{d \int_{0}^{1} V(k)}{d \bar{k}_{s}}+\alpha \frac{\partial U^{l}}{\partial g_{l}} \frac{d g_{l}}{d \bar{k}_{s}}+\frac{\partial U^{s}}{\partial g_{s}} \frac{d g_{s}}{d \bar{k}_{s}}\right]=0 .
$$

Focusing on the case when $\bar{k}_{l}>\bar{k}_{s}$ we have $\frac{d \int_{0}^{1} V((k) d k}{d \bar{k}_{s}}=-x\left(q\left(\bar{k}_{s}\right)=1+\tau_{s}+\tau_{l}\right) \equiv-x_{l s}$ Then substituting for $\frac{d g_{s}}{d \bar{k}_{s}}$ and $\frac{d g_{l}}{d \bar{k}_{s}}$ using (2.7) in (A.21) yields

$\bar{k}_{s} W_{\bar{k}_{s}}^{s}=\bar{k}_{s} \tau_{s}\left[\left(M R S_{s}-1\right) x_{l s}+M R S_{s} \tau_{s}\left(k_{s} x_{21}^{s}+k_{l s} x_{21}^{l s}\right)+\alpha M R S_{l} \tau_{l}\left(x_{11}^{l s}+\left(k_{l} x_{21}^{l}+k_{l s} x_{21}^{l s}\right)\right)\right]=0$.

where $\tau_{s} \hat{x}_{11}^{l s} \approx x_{l s}-x_{l}$. Then multiplying (A.22) by $\left(k_{s}+k_{l s}\right)$ and then subtracting the first order condition (2.14) from it after simplifying gives

$$
W_{\bar{k}_{s}}^{s}=\tau_{s}\left[\tau_{s}\left[M R S_{s} k_{l s} x_{l s}+k_{s} x_{s}\right]\left(-\hat{x}_{11}\right)+\alpha M R S_{l} \tau_{l} x_{l s} k_{s} \hat{x}_{11}\right]
$$

Then as can be seen from (A.23) when $k_{s}=0 W_{\bar{k}_{s}}^{s}>0$. 


\section{A.3 Derivations for Section 3 (Optimal Division and Co-Occupancy)}

\section{A.3.1 Derivations for Section 3.1 (Optimal Division)}

Differentiating (3.5) with respect to $\bar{k}_{l}$ with $\bar{k}_{l}=1-\bar{k}_{s}$ gives

$$
W_{\bar{k}_{l}}=\left[\left.\frac{d \int_{0}^{1} V(q(k)) d k}{d \bar{k}_{l}}\right|_{\bar{k}_{l}=1-\bar{k}_{s}}+\left.M R S_{s} \frac{d g_{s}}{d \bar{k}_{l}}\right|_{\bar{k}_{l}=1-\bar{k}_{s}}+\left.M R S_{l} \frac{d g_{l}}{d \bar{k}_{l}}\right|_{\bar{k}_{l}=1-\bar{k}_{s}}\right]=0
$$

Then using $\left.\frac{d \int_{0}^{1} V(q(k)) d k}{d \bar{k}_{l}}\right|_{\bar{k}_{l}=1-\bar{k}_{s}}=V_{y}\left(\tau_{l} x_{l}-\tau_{s} x_{s}\right)$ and (2.7) to substitute for $\left.\frac{d g_{s}}{d \bar{k}_{l}}\right|_{\bar{k}_{l}=1-\bar{k}_{s}}$ and $\left.\frac{d g_{l}}{d \bar{k}_{l}}\right|_{\bar{k}_{l}=1-\bar{k}_{s}}$ and simplifying gives (3.3).

\section{A.3.2 Proof of Proposition 4}

Part a)

i) If $\alpha=0$ then with $\bar{k}_{l}=\bar{k}_{s}=.5$ from (2.11) and (2.14) we obtain

$$
M R S_{l}=\frac{1}{\left[1+\tau_{l}\left(\hat{x}_{11}+.5 \hat{x}_{21}\right)\right]}>(<) \frac{1}{\left[1+\tau_{s}\left(\hat{x}_{11}+.5 \hat{x}_{21}\right)\right]}=M R S_{s} \text { if } \tau_{l}>(<) \tau_{s}
$$

Then with $\hat{x}_{21}>0$ it is apparent from (3.3) that $\left.W_{\bar{k}_{l}}\right|_{\bar{k}_{l}=.5}>0$. Then with the assumption that $\frac{d \frac{1}{\left[1+\tilde{\tau}_{j}\left(\eta_{11}+.5 \eta_{21}\right)\right]}}{d \tau_{j}}>0, j=l, s$ it follows that if $\tau_{l}(.5)>(<) \tau_{s}(.5)$ that $\bar{k}_{l}^{*}>(<) .5$. It will be useful when considering the possibility of co-occupancy to use the first order conditions for the taxes to express (3.2) as

$$
\left.W_{\bar{k}_{l}}\right|_{\bar{k}_{s}=1-\bar{k}_{l}}=\left(M R S_{l} \tau_{l}^{2} x_{l}-M R S_{s} \tau_{s}^{2} x_{s}\right)\left(-\hat{x}_{11}\right)+\tau_{l} \tau_{s}\left(M R S_{s} k_{s} x_{s}-(1-\alpha) M R S_{l} k_{l} x_{l}\right) \hat{x}_{21}=0
$$

If $\hat{x}_{21}<0$ using (2.11) and (2.14) to substitute for $M R S_{l}$ and $M R S_{s}$ in the second term of (A.26) gives

$$
\left.W_{\bar{k}_{l}}\right|_{\bar{k}_{s}=1-\bar{k}_{l}}=\left(M R S_{l} \tau_{l}^{2} x_{l}-M R S_{s} \tau_{s}^{2} x_{s}\right)\left(-\hat{x}_{11}\right)+\frac{\tau_{l} \tau_{s}}{D_{L} D_{s}}\left(\tau_{l}-\tau_{s}\right)\left(x_{11}+.5 x_{21}\right) \hat{x}_{21}>(<) 0
$$

as $\tau_{l}(.5)>(<) \tau_{s}(.5)$.

ii) If $\bar{k}_{l}^{*}>(<) .5$ from inspection of (3.3) it is apparent that with $x_{21}>0$ that it cannot be satisfied with $\tau_{l}\left(\bar{k}_{l}^{*}\right)>\tau_{s}\left(\bar{k}_{l}^{*}\right)$ and $M R S_{l}\left(\bar{k}_{l}^{*}\right)>\operatorname{MRS}\left(\bar{k}_{l}^{*}\right)$ or $\tau_{l}\left(\bar{k}_{l}^{*}\right)<\tau_{s}\left(\bar{k}_{l}^{*}\right)$ and $\operatorname{MRS}_{l}\left(\bar{k}_{l}^{*}\right)<M R S_{s}\left(\bar{k}_{l}^{*}\right)$. Then either it is the case that $\tau_{l}\left(\bar{k}_{l}^{*}\right)>\tau_{s}\left(\bar{k}_{l}^{*}\right)$ and $M R S_{l}\left(\bar{k}_{l}^{*}\right)<M R S_{s}\left(\bar{k}_{l}^{*}\right)$ or $\tau_{l}\left(\bar{k}_{l}^{*}\right)<\tau_{s}\left(\bar{k}_{l}^{*}\right)$ and $M R S_{l}\left(\bar{k}_{l}^{*}\right)>M R S_{s}\left(\bar{k}_{l}^{*}\right)$. Suppose 
that $\bar{k}_{l}^{*}>.5$ then if $\tau_{l}\left(\bar{k}_{l}^{*}\right)<\tau_{s}\left(\bar{k}_{l}^{*}\right)$ then $M R S_{l}\left(\bar{k}_{l}^{*}\right)<M R S_{s}\left(\bar{k}_{l}^{*}\right)$. However, if $\tau_{l}\left(\bar{k}_{l}^{*}\right)>\tau_{s}\left(\bar{k}_{l}^{*}\right)$ with sufficiently large $\bar{k}_{l}^{*}>.5$ then $M R S_{l}\left(\bar{k}_{l}^{*}\right)<M R S_{s}\left(\bar{k}_{l}^{*}\right)$.

Part b)

i) and ii) Using (2.11) and (2.14) to substitute for $M R S_{l}$ and $M R S_{s}$ in (A.26) with $\alpha=1$ gives

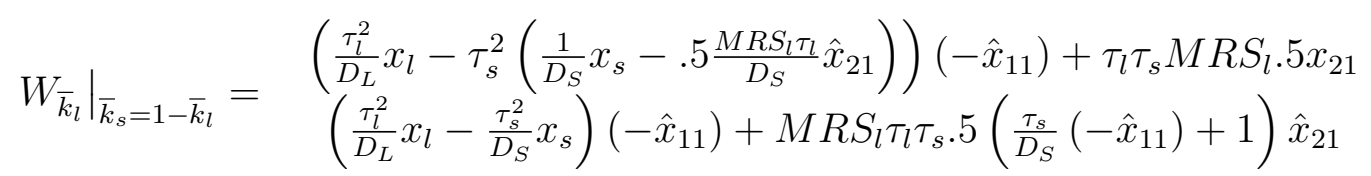

where the sign of the second term of (A.28) is the sign of $\hat{x}_{21}$ and the sign of the first term is the sign of $\tau_{l}(.5)-\tau_{s}(.5)$.

iii) and iv) That $\tau_{l}\left(\bar{k}_{l}^{*}\right)<\tau_{s}\left(\bar{k}_{l}^{*}\right)$ if $x_{21}>0$ and $\tau_{l}\left(\bar{k}_{l}^{*}\right)>\tau_{s}\left(\bar{k}_{l}^{*}\right)$ if $x_{21}<0$ follows from inspection of (A.28) as the first term must have the opposite sign of the second term to have $\left.W_{\bar{k}_{l}}\right|_{\bar{k}_{s}=1-\bar{k}_{l}}=0$.

\section{A.3.3 Proof of Proposition 5}

Part b) follows from inspection of (3.8) - (3.9).

Part c)

ii) Subtracting (A.26) from (3.8)

$$
\left.W_{\bar{k}_{l}}\right|_{\bar{k}_{l}=\bar{k}_{l}^{*}}=\left[\begin{array}{c}
M R S_{l} \tau_{l}^{2 *}\left(x_{l s}-x_{l}\right)\left(-\hat{x}_{11}\right)+M R S_{s} \tau_{s}^{*}\left(\tau_{l}^{*} x_{l s}-\tau_{s}^{*} x_{s}\right)\left(-\hat{x}_{11}\right) \\
+\tau_{l}^{*} \tau_{s}^{*} M R S_{s} k_{s}\left(x_{l s}-x_{s}\right) \hat{x}_{21}+(1-\alpha) M R S_{l} \tau_{l}^{*} k_{s} \hat{x}_{21}
\end{array}\right] .
$$

The first and fourth terms are clearly negative, the third term is positive and the second term is ambiguous. Then using $x_{s} \approx x_{l s}\left(1-\tau_{l} \hat{x}_{11}\right)$ yields

$$
\begin{aligned}
& M R S_{s} \tau_{s}^{*}\left[\left(\tau_{l}^{*} x_{l s}-\tau_{s}^{*} x_{s}\right)\left(-\hat{x}_{11}\right)+\tau_{l}^{*} k_{s}\left(x_{l s}-x_{s}\right) \hat{x}_{21}\right] \\
& \quad \simeq M R S_{s} \tau_{s}^{*}\left(\tau_{l}^{*}-\tau_{s}^{*}+\tau_{s}^{*} \tau_{l}^{*} \hat{x}_{11}\left(1+k_{s} \tau_{l}^{*} \hat{x}_{21}\right)\right)
\end{aligned}
$$

with an analogous approximation for $-\left.W_{\bar{k}_{s}}\right|_{\bar{k}_{l}=\bar{k}_{l}^{*}}$.

\section{A.3.4 Derivations for Section 3.3 (Leadership in Determination of the Tax Base)}

\section{Tax Reactions with No Co-occupancy}

Totally differentiating $(2.11)$ with respect to $\bar{k}_{l}$ yields 


$$
\frac{\partial^{2} W^{l}}{\partial \tau_{l}^{2}} \frac{d \tau_{l}}{d \bar{k}_{l}}+\frac{\partial^{2} W^{l}}{\partial \tau_{l} \partial \tau_{s}} \frac{d \tau_{s}}{d \bar{k}_{l}}+\frac{\partial^{2} W^{l}}{\partial \tau_{l} \partial \bar{k}_{l}}=0
$$

and differentiating (2.14) yields

$$
\frac{\partial^{2} W^{s}}{\partial \tau_{s}^{2}} \frac{d \tau_{s}}{d \bar{k}_{l}}+\frac{\partial^{2} W^{s}}{\partial \tau_{s} \partial \tau_{l}} \frac{d \tau_{l}}{d \bar{k}_{l}}+\frac{\partial^{2} W^{s}}{\partial \tau_{s} \partial \bar{k}_{l}}=0
$$

Solving (A.31) and (A.32) for $\frac{d \tau_{l}}{d \bar{k}_{l}}$ and $\frac{d \tau_{s}}{d \bar{k}_{l}}$ gives

$$
\begin{gathered}
\frac{d \tau_{l}}{d \bar{k}_{l}}=\frac{-\frac{\partial^{2} W^{l}}{\partial \tau_{l} \partial \bar{k}_{l}} \frac{\partial^{2} W^{s}}{\partial \tau_{s}^{2}}+\frac{\partial^{2} W^{l}}{\partial \tau_{l} \partial \tau_{s}} \frac{\partial^{2} W^{s}}{\partial \tau_{s} \partial \bar{k}_{l}}}{|A|} \text { and } \\
\frac{d \tau_{s}}{d \bar{k}_{l}}=\frac{-\frac{\partial^{2} W^{s}}{\partial \tau_{l} \partial \bar{k}_{l}} \frac{\partial^{2} W^{l}}{\partial \tau_{l}^{2}}+\frac{\partial^{2} W^{s}}{\partial \tau_{s} \partial \tau_{l}} \frac{\partial^{2} W^{l}}{\partial \tau_{l} \partial \bar{k}_{l}}}{|A|}
\end{gathered}
$$

where $\frac{\partial^{2} W^{l}}{\partial \tau_{l}^{2}}>0, \frac{\partial^{2} W^{s}}{\partial \tau_{s}^{2}}>0$, and $|A|=\left|\begin{array}{cc}\frac{\partial^{2} W^{l}}{\partial \tau_{l}^{2}} & \frac{\partial^{2} W^{l}}{\partial \tau_{l} \partial \tau_{s}} \\ \frac{\partial^{2} W^{s}}{\partial \tau_{l} \partial \tau_{s}} & \frac{\partial^{2} W^{s}}{\partial \tau_{s}^{2}}\end{array}\right|>0$ by the second order conditions. Then

$$
\begin{aligned}
& \frac{\partial^{2} W^{l}}{\partial \tau_{l} \partial \tau_{s}}=M R S_{l} \frac{\partial M R S_{l}}{\partial g_{l}} \frac{\left[\tau_{l} k_{l} x_{21}^{l} k_{s}\right]}{M R S_{l}}=M R S_{l} \epsilon_{l} \hat{x}_{21} k_{s} \\
& \begin{aligned}
\frac{\partial^{2} W^{s}}{\partial \tau_{l} \partial \tau_{s}}=\left[\begin{array}{c}
\frac{\partial M R S_{s}}{\partial g_{s}}\left[k_{s} x_{21} k_{l}\right]\left[1+\tau_{s}\left(\hat{x}_{11}+k_{s} \hat{x}_{21}\right)\right] \\
+(1-\alpha) M R S_{l}\left[k_{l} x_{21}+\frac{\partial M R S_{l}}{\partial g_{l}} \frac{\tau_{l} k_{l}\left(x_{11}+k_{l} x_{21}\right)}{M R S_{l}}\right]
\end{array}\right] \\
=\left[\begin{array}{c}
M R S_{s} \epsilon_{s} k_{l} \hat{x}_{21}\left[1+\tau_{s}\left(\hat{x}_{11}+k_{s} \hat{x}_{21}\right)\right]+ \\
(1-\alpha) M R S_{l}\left[k_{l} \hat{x}_{21}+\epsilon_{l}\left(\hat{x}_{11}+k_{l} \hat{x}_{21}\right)\right]
\end{array}\right]
\end{aligned} \\
& \begin{array}{c}
\frac{\partial^{2} W^{l}}{\partial \tau_{l} \partial \bar{k}_{l}}=M R S_{l} \tau_{l} \hat{x}_{21}+\frac{\partial M R S_{l}}{\partial g_{l}} \frac{1}{M R S_{l}}\left[\tau_{l} x_{l}+\tau_{l} \eta_{21} x_{21}\left(\epsilon_{l}-\epsilon_{s}\right)\right] \\
\left.\left.k_{l}+\hat{x}_{21}\left(\tau_{l}-\tau_{s}\right)\right]\left[1+\tau_{l}\left(\hat{x}_{11}+k_{l} \hat{x}_{21}\right)\right]\right], \text { and }
\end{array} \\
& -M R S_{s} \tau_{s} \hat{x}_{21}+\frac{\partial M R S_{s}}{\partial g_{s}} \frac{1}{M R S_{s}}\left[-\tau_{s} x_{s}+\tau_{s} k_{s} x_{21}\left(\tau_{l}-\tau_{s}\right)\right] \\
& \underline{\partial^{2} W^{s}}=+(1-\alpha) M R S_{l}\left[\tau_{l} \hat{x}_{21}+\frac{\partial M R S_{l}}{\partial g_{l}} \frac{1}{M R S_{l}}\left[\tau_{l} x_{l}+\tau_{l} k_{l} x_{21}\left(\tau_{l}-\tau_{s}\right)\right]\right]
\end{aligned}
$$

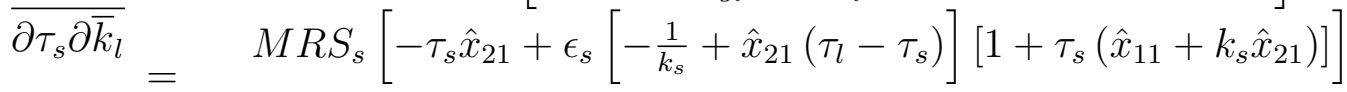

$$
\begin{aligned}
& +(1-\alpha) M R S_{l} \tau_{l} \hat{x}_{21}\left[1+\epsilon_{l}\left[1+\hat{x}_{21} k_{l}\left(\tau_{l}-\tau_{s}\right)\right]\left[1+\tau_{l}\left(\hat{x}_{11}+k_{l} \hat{x}_{21}\right)\right]\right]
\end{aligned}
$$


Tax Reaction Functions with Overlap (at $k_{l s}=0$ ).

Expressions (A.31) - (A.36) are identical for the case without and with co-occupancy. Then in contrast to the case without co-occupancy

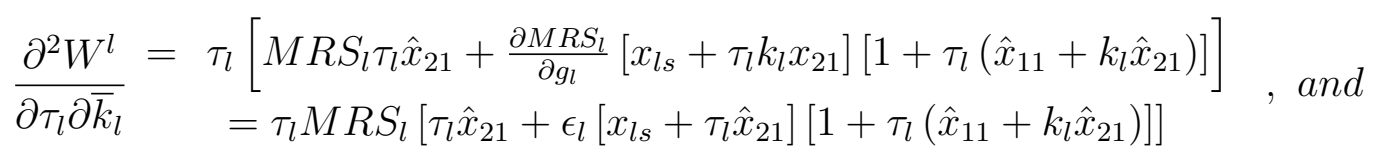

$$
\begin{aligned}
& \begin{aligned}
&= {\left[M R S_{s} \tau_{s} \tau_{l} \hat{x}_{21}+\frac{\partial M R S_{s}}{\partial g_{s}} \frac{1}{M R S_{s}}\left[\tau_{s}\left(x_{l s}-x_{s}\right)+\tau_{s} \tau_{l} k_{s} x_{21}\right]\right] } \\
& \frac{\partial^{2} W^{s}}{\partial \tau_{s} \partial \bar{k}_{l}}+(1-\alpha) \tau_{l} M R S_{l}\left[\tau_{l} \hat{x}_{21}+\frac{\partial M R S_{l}}{\partial g_{l}} \frac{1}{M R S_{l}}\left[\tau_{l} x_{l}+\tau_{l} k_{l} x_{21}\left(\tau_{l}-\tau_{s}\right)\right]\right] \\
&= M R S_{s}\left[-\tau_{s} \hat{x}_{21}+\epsilon_{s}\left[-\frac{1}{k_{s}}+\hat{x}_{21}\left(\tau_{l}-\tau_{s}\right)\right]\left[1+\tau_{s}\left(\hat{x}_{11}+k_{s} \hat{x}_{21}\right)\right]\right] \\
&+(1-\alpha) M R S_{l} \tau_{l} \hat{x}_{21}\left[1+\epsilon_{l}\left[1+\hat{x}_{21} k_{l}\left(\tau_{l}-\tau_{s}\right)\right]\left[1+\tau_{l}\left(\hat{x}_{11}+k_{l} \hat{x}_{21}\right)\right]\right]
\end{aligned}
\end{aligned}
$$

\section{A.3.5 Derivations for Section 3.4 (Differential State Taxation)}

The derivation of the first order conditions for the state tax rates, (3.17) and (3.18) follows the approach in deriving the state and local tax rates in when they are uniform. Total differentiating welfare with respect to $\tau_{s}^{s}$ gives

$$
W_{\tau_{s}^{s}}=\begin{aligned}
& \left(M R S_{s}-1\right) k_{s} x_{s}+M R S_{s} \tau_{s}^{s}\left(k_{s} x_{11}^{s}+k_{s}^{2} x_{21}^{s}\right)+ \\
& +M R S \tau_{s}^{l s} k_{s} k_{l s} x_{21}^{l s}+M R S_{l} \tau_{l} k_{s}\left(k_{l} x_{21}^{l}+k_{l s} x_{21}^{l s}\right)
\end{aligned}=0
$$

which can be expressed as

$$
W_{\tau_{s}^{s}}=\begin{gathered}
\left(M R S_{s}-1\right) k_{s} x_{s}+M R S_{s} \tau_{s}^{s} k_{s} x_{s}\left(\hat{x}_{11}+k_{s} \hat{x}_{21}\right)+ \\
+M R S \tau_{s}^{l s} k_{s} k_{l s} x_{l s} \hat{x}_{21}+M R S_{l} \tau_{l} k_{s}\left(k_{l} x_{l} \hat{x}_{21}+k_{l s} x_{l s} \hat{x}_{21}\right)
\end{gathered}=0
$$

Then dividing by $k_{s} x_{s}$ and letting $\left(k_{l} x_{l} \hat{x}_{21}+k_{l s} x_{l s} \hat{x}_{21}\right) \equiv\left(k_{l}+k_{l s}\right) \bar{x} \hat{x}_{21}$ gives (3.17). The first order condition for the state tax on the shared base, (3.18), is derived similarly.

Deriving the impacts of expansions of the local tax base and the state tax base, (3.19) and (3.20) also follows the approach in deriving them with uniform tax rates.

\section{A.4 Derivations for Section 4 (Tax Assignment with Horizontal Externalities)}

\section{A.4.1 Optimal Assignment}

Evaluating (4.6) at $k_{l s}=0$ gives 


$$
\frac{d W}{d \tau_{l}}=V_{y} X_{l}\left[-M R S_{l} \tau_{l} X_{l} \hat{N}_{\tau_{l}}+M R S_{s} \tau_{s} k_{s} \frac{\bar{x}_{s}}{\bar{x}_{l}} \hat{x}_{21}+M R S_{l} \tau_{l} \tau_{s} k_{s} \hat{\tau}_{s} \hat{x}_{21}\right]
$$

If $\left|\hat{\tau}_{s}\right|<1$ and if $\hat{x}_{21}>0$ clearly (A.43) is positive. Differentiating (4.5) with respect to a uniform change in $\tau_{l}$ with respect to $\hat{N}_{\tau_{l}}$ gives

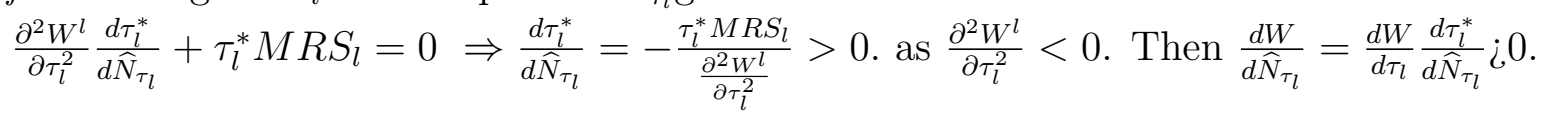

\section{A.4.2 Optimal Division of the Tax Base}

Differentiating social welfare with respect to $\bar{k}_{l}$ where $\bar{k}_{s}=1-k_{l}$ gives

$$
\begin{gathered}
\tau_{l}^{*}\left[\begin{array}{cc}
\left(-1+M R S_{l}\left(1+\tau_{l}^{*} k_{l} \hat{x}_{21}\right)\right) x_{l} & \\
(a) & M R S_{s} \tau_{s}^{*} k_{s} x_{s} \hat{x}_{21} \\
\tau_{s}^{*} & (b)
\end{array}\right]= \\
\left(\begin{array}{cc}
\left(-1+M R S_{s}\left(1+\tau_{s}^{*} k_{s} \hat{x}_{21}\right)\right) x_{s} & \\
(c) & M R S_{l} \tau_{l}^{*} k_{l} x_{l} \hat{x}_{21}
\end{array}\right]
\end{gathered}
$$

in equilibrium as in the case of no cross-border shopping. In this case, however, we have $\left(-1+M R S_{l}\left(1+\tau_{l}^{*} k_{l} \hat{x}_{21}\right)\right) x_{l}=-\left(\tau_{l}\left(\hat{x}_{11}+\widehat{N}_{\tau_{l}}\right)\right) x_{l}$ using the first order condition for the local taxes (4.5). Then making this substitution and substituting for $\left(-1+M R S_{s}\left(1+\tau_{s}^{*} k_{s} \hat{x}_{21}\right)\right) x_{s}$ using (2.14) gives (4.7). 